\title{
A systematic framework for assessing the applicability of reactive distillation for quaternary mixtures using a mapping method
}

DOI:

10.1016/j.compchemeng.2020.106804

\section{Document Version \\ Accepted author manuscript}

Link to publication record in Manchester Research Explorer

Citation for published version (APA):

Muthia, R., Jobson, M., \& Kiss, A. (2020). A systematic framework for assessing the applicability of reactive distillation for quaternary mixtures using a mapping method. Computers \& Chemical Engineering.

https://doi.org/10.1016/j.compchemeng.2020.106804

\section{Published in:}

Computers \& Chemical Engineering

\section{Citing this paper}

Please note that where the full-text provided on Manchester Research Explorer is the Author Accepted Manuscript or Proof version this may differ from the final Published version. If citing, it is advised that you check and use the publisher's definitive version.

\section{General rights}

Copyright and moral rights for the publications made accessible in the Research Explorer are retained by the authors and/or other copyright owners and it is a condition of accessing publications that users recognise and abide by the legal requirements associated with these rights.

\section{Takedown policy}

If you believe that this document breaches copyright please refer to the University of Manchester's Takedown Procedures [http://man.ac.uk/04Y6Bo] or contact uml.scholarlycommunications@manchester.ac.uk providing relevant details, so we can investigate your claim.

\section{OPEN ACCESS}


1 A systematic framework for assessing the applicability of reactive distillation for quaternary mixtures using a mapping method

\author{
Rahma Muthia ${ }^{1}$, Megan Jobson ${ }^{1}$, Anton A. Kiss ${ }^{1,2 *}$
}

${ }^{1}$ Department of Chemical Engineering and Analytical Science, The University of Manchester, Sackville Street, Manchester, M13 9PL, United Kingdom

${ }^{2}$ Sustainable Process Technology Group, Faculty of Science and Technology, University of Twente, PO Box 217, 7500 AE, Enschede, The Netherlands

*Corresponding author: tony.kiss@manchester.ac.uk, Tel: +44 1613068759

\title{
Keywords
}

Feasibility assessment, conceptual design, process synthesis, azeotropic systems

\section{Highlights}

- New systematic framework for evaluating the applicability of reactive distillation

- Mapping method is used to screen reactive distillation designs in non-ideal systems

- Case studies covering non-ideal quaternary systems with various boiling point ranking

\section{Abstract}

Reactive distillation (RD) is a useful process intensification technique used in the chemical process industries as it offers important advantages such as energy and cost savings, relative to conventional technologies. However, industrial application of RD is still limited by the complexity of designing and understanding such a complex process. While simple, robust shortcut design methods that require only basic information (such as the relative volatility of components) exist for conventional distillation, such methods for evaluating the applicability of RD are not yet established.

This work fills this gap by presenting a new systematic framework for assessing the RD applicability based on a mapping method. The method enables RD designs to be screened using only relative volatilities and chemical equilibrium constant as input data. The evaluation focuses on reactions involving four components $(\mathrm{A}+\mathrm{B} \rightleftharpoons \mathrm{C}+\mathrm{D})$ with various boiling point orders, which are of most industrial importnace. The proposed systematic framework is validated through its application to five case studies, (trans-)esterifications presenting various separation challenges due to the formation of azeotropes. This novel approach offers a valuable aid for engineers in taking an educated go/no-go decision in the very initial stages of conceptual design, before performing any rigorous simulations of RD flowsheets. 


\section{1. Introduction}

3 Process intensification - comprising the development of apparatus and techniques in the chemical industries - is crucial for delivering cheaper, smaller, more energy-efficient, safer and sustainable technologies (Stankiewicz and Moulijn, 2000). It also paves the way to fulfill the chemical industry demands, especially in the context of globalization and sustainability (Charpentier, 2007). Among the available process intensification units, reactive distillation (RD), which integrates reaction and separation in a single column, as illustrated in Figure 1, has demonstrated significant contribution to process efficiency (Kiss et al., 2019). The benefits of reactive distillation, compared to conventional technologies involving a sequence of reaction and separation units, include: 1) increased conversion and selectivity, 2) lower capital investment due to the reduced number of the process units, 3) significant energy savings, by utilizing the heat of exothermic reactions for vaporization, and 4) reduced health, safety and environmental risks because of lower emissions, avoidance of reactor hot spots and reduces risk of runaway reactions (Tuchlenski et al., 2001; Harmsen, 2007; Shah et al., 2012; Kiss, 2016, 2017).

Over the past decade, over 1,000 research manuscripts explored the development of reactive distillation (Wierschem and Górak, 2018; Kiss, 2019), considering modelling of RD for specific systems (Khan and Adewuyi, 2019), process optimization and control (Sneesby et al., 1997; Sharma and Singh, 2010), pilot-scale experiments (Keller et al., 2012), the selection of catalysts and operating parameters for desired reactions (Chiu et al., 2006; Kiss et al., 2008) and column internals (Subawalla et al., 1997; Götze et al., 2001).

Nevertheless, commercial application of reactive distillation remains challenging due to the complexities in the synthesis, design, and operation of RD columns (Chen et al., 2000; Li et al., 2012; Li et al., 2016). Multiple interactions between vapor-liquid equilibrium, mass transfer, intra-catalyst diffusion in heterogeneous catalyzed processes and chemical kinetics inhibit the rapid assessment of reactive distillation designs (Taylor and Krishna, 2000). Various methods for designing RD systems have emerged since the late 1980s; these can be classified as graphical, optimization and heuristic approaches (Barbosa and Doherty, 1988a; Barbosa and Doherty, 1988b; Almeida-Rivera et al., 2004; Kiss, 2016, 2017). For example, Lee et al. (2000) developed a graphical approach, based on the modified Ponchon-Savarit and McCabe-Thiele methods, to assess the location of reactive zones in reactive distillation for binary reactions. Urselmann et al. (2011) introduced a memetic algorithm to optimize the design of reactive distillation for the production of methyl tert-butyl ether, concerning the 
1 total annual cost. Subawalla and Fair (1999) suggested guidelines, based on a generic

standpoint and heuristic approaches, for determining the design parameters of reactive distillation in solid-catalyzed systems. Other design methods are reported in the open literature (including Ung and Doherty, 1995; Giessler et al., 1998; Thery et al., 2005; Damartzis and Seferlis, 2010; Jantharasuk et al., 2011; Amte et al., 2013; Kiss, 2016, 2017). However, the results of rigorous calculations and simulations in those methods are usually only applied to a certain reaction system; repetitive calculations are required to evaluate reactive distillation for other chemical systems. Therefore, designing a reactive distillation process can be time-consuming and complex (Segovia-Hernández et al., 2015).

In conventional distillation processes, shortcut models are used to initialize column designs. Models, such as the Fenske-Underwood-Gilliland method, determine the minimum number of theoretical stages, minimum reflux ratio and number of theoretical stages required for a given reflux ratio. The models employ relative volatility of compounds $(\alpha)$ to characterize the separation performance in the column. The relative volatility can be quantified from the feed composition. Alternatively, it can be taken as an average value at the top and bottom streams based on their compositions. Non-ideal vapour-liquid equilibrium behavior in the system reduces the accuracy of the shortcut models' predictions; greater errors are generally observed in more non-ideal systems (Smith, 2016). However, the shortcut models are robust and can be solved quickly (Towler and Sinnott, 2012), and hence, are a good basis for generating initial column designs and for initializing rigorous models. To the best of our knowledge, unlike for conventional distillation, methods that use some key parameters to evaluate reactive distillation designs are not well established. Rigorous simulations and calculations are usually needed to investigate the applicability of reactive distillation to each reaction system.

The present work proposes a new systematic framework for assessing the applicability of reactive distillation to azeotropic (non-ideal) quaternary reaction systems, $\mathrm{A}+\mathrm{B} \rightleftharpoons \mathrm{C}+\mathrm{D}$, with various rankings of boiling points, only based on hypothetical and ideal cases using few key parameters, namely relative volatilities of compounds, chemical equilibrium constants and Damköhler number. The approach is called the mapping method, and it was introduced by our prior study (Muthia et al., 2018a), but the scope of that study was limited to ideal quaternary reaction systems for only a subset of boiling point orders, $T_{b, C}<T_{b, A}<T_{b, B}<T_{b, D}$. The mapping method features a plot of reflux ratio vs. number of theoretical stages to define an 'applicable region', in which reactive distillation could potentially be employed for a certain chemical system. The applicability of reactive distillation is assessed using preprepared applicability graphs of 'generic' cases, corresponding to hypothetical components 
1 and ideal reaction systems. To assess a 'real' system, the user needs basic information, i.e., characteristic values of relative volatilities and the chemical equilibrium constant of the real system of interest.

Previous studies, such as Barbosa and Doherty (1988a, 1988b) have developed a set of transformed composition variables to calculate the minimum reflux ratios for single- and double-feeds reactive distillation columns. Giessler et al. (1998) proposed a method called statics analysis that enables the calculation of the number of theoretical stages based on thermodynamic-topological analysis of distillation diagrams. However, those methods only provide reflux ratio and the number of theoretical stages for a single configuration. This novel work provides a systematic approach to generate applicability graphs of reactive distillation (for any system of interest), which contain all possible RD configurations with various number of theoretical stages and reflux ratios. Note that only one applicability graph is generated for each chemical system and that graph can be used multiple times by end-users (engineers) to design different RD configurations.

The present work demonstrates the new framework by applying it to five case studies exhibiting different separation challenges arising due to the presence of azeotropes. These case studies serve to validate the proposed framework, in terms of its ability to estimate the applicable region for RD in a given quaternary system with non-ideal behaviour.

\section{Mapping method overview}

This work presents a systematic framework that applies our novel mapping method, for screening and initialization of reactive distillation column designs. The mapping method (Muthia et al., 2018a, 2019a) has been introduced and demonstrated in near-ideal quaternary systems with the reaction $\mathrm{A}+\mathrm{B} \rightleftharpoons \mathrm{C}+\mathrm{D}$. Initially the approach was demonstrated for systems with boiling point order $\mathrm{T}_{\mathrm{b}, \mathrm{C}}<\mathrm{T}_{\mathrm{b}, \mathrm{A}}<\mathrm{T}_{\mathrm{b}, \mathrm{B}}<\mathrm{T}_{\mathrm{b}, \mathrm{D}}$ (Muthia et al., 2018a), where the two products are the lightest (C) and heaviest (D) components in the system and so are readily separated from each other. A subsequent study demonstrated the approach for systems with other boiling point orders (Muthia et al., 2019b) and provided some insights into the optimal feed locations of reactive distillation columns.

The main feature of the mapping method is the applicability graph of reactive distillation designs, which is a plot of reflux ratio vs. the number of theoretical stages, as illustrated in Figure 2(a). A boundary line in an applicability graph identifies the lowest reflux ratios possible for various numbers of theoretical stages. The 'applicable area' represents multiple column configurations each with a certain number of rectifying, reactive and stripping stages, 
where some very dissimilar configurations may have very similar reflux ratios for an identical number of theoretical stages. For example, see Figure S1 and Table S1 in the Supporting Information.

As demonstrated for near-ideal quaternary systems (Muthia et al., 2018a), the method is capable of predicting the applicability area for reactive distillation of real systems based only on pre-prepared applicability graphs of generic cases. In these idealized, hypothetical generic cases, the relative volatilities and chemical equilibrium constants are fixed and independent of process temperatures. This work aims to demonstrate that real (non-ideal) systems can also be addressed by the method, in particular for cases involving the presence of azeotropes, as these systems are industrially important.

Figure 2(b) illustrates application of the method: the user must select the most relevant generic cases, i.e. where the representative relative volatilities and chemical equilibrium constant are similar to those of the real system being assessed. The shaded area in Figure 2(b) represents the location in which the actual boundary line is expected to lie. Thus, the user can read from the plot approximate values of the reflux ratio and numbers of stages required in the reactive distillation column. Note that the mapping method predicts the number of theoretical stages and reflux ratio, but not the column configuration. The multiple possibles configurations represent an opportunity for reactive distillation column design.

Figure 3 summarizes the methodology developed in this work, which has three directions for: (1) the generation of applicability maps, (2) the validation of the maps using case studies, and (3) the actual use of the generic maps by end-users to determine the applicability of reactive distillation for new cases. For the purpose of the validation of the proposed method, in this study, the generation of generic applicability graphs is only performed for relevant generic cases with the representative relative volatilities and chemical equilibrium constants that are similar to those of case studies.

The generation of generic applicability graphs and the validation of the mapping method in this study require extensive simulations for both generic cases and case studies, in which reactive distillation configurations are generated in Aspen Plus process simulation software using the RadFrac model. In the simulations for the generation of generic maps, hypothetical chemical components A, B, C and D are defined, the ideal property model is selected, and the boiling points and the Antoine coefficients of defined hypothetical components are changed for the specified relative volatilities set. Next, fixed equilibrium (and reaction rate) constants are input to the simulation software. An equimolar feed of the reactants (A and B) is fed to a reactive distillation column in which each separation stage is assumed to reach phase 
1 equilibrium and each reactive stage is assumed to reach both reaction and phase equilibria.

2 The purity of the product streams is specified (99 mol\%), i.e. the overall material balance is

3 fixed. The mixture is modelled as an ideal mixture but the column is modelled rigorously material and energy balances are carried out on each stage, informed by equilibrium calculations.

Note that the simulations are all carried out for a 'simple' reactive distillation, with a structure such as that shown in Figure 1(a). The column operates at atmospheric pressure with fixed feed inlets at the top and the bottom stages of the reactive section. To obtain multiple configurations, the numbers of rectifying, reactive and stripping stages are varied for each number of theoretical stages by using the sensitivity analysis block. For each configuration, the optimization tool in Aspen Plus is simultaneously employed to minimize the reflux ratio under the constraint of product purity $\geq 99 \mathrm{~mol} \%$. Among all possible configurations, the lowest reflux ratio is manually selected for each number of theoretical stages. The lowest energy for all numbers of theoretical stages form a boundary line of an applicability area. To validate the method, in this study, the predictions of the applicability graph are compared with the results of rigorous simulations for the case studies. These simulations, carried out in Aspen Plus, take into account real chemical components, the phase equilibrium behavior (i.e. constant relative volatility is not assumed) and reaction behavior (e.g. reaction kinetics or dependence of equilibrium conversion with temperature and composition are accounted for). Similar to that conducted for the generic case, sensitivity and optimization blocks, are employed for the case study, in which various column configurations - with various numbers of rectifying, stripping and reactive stages - are modelled for different numbers of theoretical stages. Once again, the feed is assumed to be an equimolar mixture of the reactants (A and B) and the purity of the products is fixed at $99 \mathrm{~mol} \%$. Depending on the properties of the mixture, various configurations may be explored. For example, feed stages at other locations than the top and bottom of the reactive zone may be selected and a liquid-liquid phase separator may be included, as shown in Figure 1(b), if it is anticipated that the overhead product is a low-boiling heterogeneous azeotrope. These validation simulations aim to identify the minimum reflux ratio required to achieve the desired material balance for a given total number of stages. The result is then compared to the boundary of the applicability region for a generic system with similar characteristic parameters (relative volatilities and reaction equilibrium constant). If the required reflux ratio for a given number of stages is similar (e.g. within 50\%) for the two cases, then it is argued that the applicability map is valid - i.e. that it is sufficiently useful for process screening to allow informed go/no-go decision-making. 
1 Prior to the use of the mapping method by end-users, a team of researchers or engineers, who

2 act as map generators, produce a bundle of many generic applicability maps with different sets of fixed relative volatilities, chemical equilibrium constants and reaction rates. Once those graphs have been created through multiple simulations in Aspen Plus, further rigorous simulations are not needed to allow the graph to be used for process screening. Note that an applicability graph of a generic case prepared once by map generators can be used afterwards multiple times by process engineers to assess the applicability of reactive distillation and design different column configurations.

End-users employ the mapping method in a similar way to a global positioning system (GPS), where determined representative relative volatilities of compounds and calculated equilibrium constant (and the Damköhler number for a kinetically controlled reaction) are overlaid onto generic applicability graphs that are pre-generated by map generators. The graphs may then be used to quantify the reflux ratio - number of stages relationship for a real system, without requiring any detailed simulation of the real system or associated reactive distillation column. In principle, the fixed parameters of the generic system should be similar to those of the real system, to get the most useful predictions.

\section{Results and discussion}

This section focuses on formulating and testing the systematic framework, by outlining the new systematic framework developed for assessing the applicability of reactive distillation columns and exploring the effectiveness of the framework for five case studies.

\subsection{A systematic framework for assessing the applicability of reactive distillation}

Figure 4 summarizes the workflow of the framework, showing the sequence of steps followed to obtain multiple reactive distillation configurations and to conduct a preliminary economic evaluation of a proposed reactive distillation application. The users of the systematic framework are expected to be process engineers in the chemical industries involved in the very early stages of conceptual process design, and who wish to explore the potential benefits of reactive distillation, while minimizing the engineering time required to assess options and identify potentially attractive design solutions. That is, the framework aims to help engineers support decision-making, while avoiding time-consuming rigorous process simulations.

The framework is designed to consider equimolar quaternary reactions $(\mathrm{A}+\mathrm{B} \neq \mathrm{C}+\mathrm{D})-$ industrial applications have already shown reactive distillation to be an attractive technology for systems of this nature (Sharma and Mahajani, 2003; Hiwale et al., 2004). At the beginning 
1 of the applicability assessment, it is crucial to identify the boiling points of the four species and to classify the quaternary mixture according to their ranking, using an established convention (Luyben and $\mathrm{Yu}, 2008$ ). Prior studies have shown a significant impact of boiling point order on the performance of reactive distillation (Chen and $\mathrm{Yu}, 2008$; Luyben and $\mathrm{Yu}$, 2008). In those studies, they conducted rigorous simulations and performed detailed economic calculation concerning only a fixed chemical equilibrium constant.

Our previous work considered a range of chemical equilibrium constants and employed a simpler approach, based on the mapping method, taking the number of theoretical stages and reflux ratio as important performance indicators for the capital investment and the energy requirement (Muthia et al., 2019b). These studies found that, in general, the likelihood of a quaternary system $(\mathrm{A}+\mathrm{B} \rightleftharpoons \mathrm{C}+\mathrm{D})$ being well suited to $\mathrm{RD}$ increases in the following order:

- Group $\mathrm{I}_{\mathrm{r}} \quad\left(\mathrm{T}_{\mathrm{b}, \mathrm{A}}<\mathrm{T}_{\mathrm{b}, \mathrm{C}}<\mathrm{T}_{\mathrm{b}, \mathrm{D}}<\mathrm{T}_{\mathrm{b}, \mathrm{B}}\right)$

- Group III $_{\mathrm{r}} \quad\left(\mathrm{T}_{\mathrm{b}, \mathrm{A}}<\mathrm{T}_{\mathrm{b}, \mathrm{C}}<\mathrm{T}_{\mathrm{b}, \mathrm{B}}<\mathrm{T}_{\mathrm{b}, \mathrm{D}}\right)$

- Group III $_{\mathrm{p}} \quad\left(\mathrm{T}_{\mathrm{b}, \mathrm{C}}<\mathrm{T}_{\mathrm{b}, \mathrm{A}}<\mathrm{T}_{\mathrm{b}, \mathrm{D}}<\mathrm{T}_{\mathrm{b}, \mathrm{B}}\right)$

- Group $\mathrm{I}_{\mathrm{p}} \quad\left(\mathrm{T}_{\mathrm{b}, \mathrm{C}}<\mathrm{T}_{\mathrm{b}, \mathrm{A}}<\mathrm{T}_{\mathrm{b}, \mathrm{B}}<\mathrm{T}_{\mathrm{b}, \mathrm{D}}\right)$.

In the most suitable class of mixtures $\left(I_{p}\right)$, the boiling point order facilitates separation of the products $\mathrm{C}$ and $\mathrm{D}$ because they have the most extreme boiling points in the mixture.

Note that reactive distillation technology is not possible for equimolar reactions in groups $\mathrm{II}_{\mathrm{p}}$ $\left(\mathrm{T}_{\mathrm{b}, \mathrm{C}}<\mathrm{T}_{\mathrm{b}, \mathrm{D}}<\mathrm{T}_{\mathrm{b}, \mathrm{A}}<\mathrm{T}_{\mathrm{b}, \mathrm{B}}\right)$ and $\mathrm{II}_{\mathrm{r}}\left(\mathrm{T}_{\mathrm{b}, \mathrm{A}}<\mathrm{T}_{\mathrm{b}, \mathrm{B}}<\mathrm{T}_{\mathrm{b}, \mathrm{C}}<\mathrm{T}_{\mathrm{b}, \mathrm{D}}\right)$, as, in these cases, the reactants (A and $B$ ) are both lighter than or both heavier than the products (C and D). As shown in Figure 4, the first step of the framework, therefore, is to identify the extent to which reactive distillation is applicable to the mixture of interest by considering the class of mixture. For mixtures in classes I and III, the user proceeds to the next step of the flowchart.

Next, the user determines characteristic values of the relative volatilities, assuming the purities of products $\mathrm{C}$ and $\mathrm{D}$ are $99 \mathrm{~mol} \%$ (where the main impurity of product $\mathrm{C}$ is the lighter reactant, $\mathrm{A}$, and the main impurity in product $\mathrm{D}$ is the heavier reactant, $\mathrm{B}$ ) and an equimolar feed (50 mol\% A and B). That is, volatilities of the products and feed $\alpha_{\mathrm{CA}}, \alpha_{\mathrm{AB}}$ and $\alpha_{\mathrm{BD}}$ need to be calculated in group $\mathrm{I}_{\mathrm{p}}$, for mixtures containing $99 \% \mathrm{C} / 1 \% \mathrm{~A}, 50 \% \mathrm{~A} / 50 \% \mathrm{~B}$ and $1 \%$ B/99\% D (Muthia et al., 2018a, 2019a).

Table 1 summarizes which volatilities need to be calculated for each class of mixture. In all cases, the volatility between reactants A and B is determined at saturated liquid conditions of the feed (with composition $50 \mathrm{~mol} \% \mathrm{~A}, 50 \mathrm{~mol} \% \mathrm{~B}$ ) and the volatility between each product 
1 and the closest-boiling reactant is determined at saturated liquid condition of the product (with composition $99 \%$ product, $1 \%$ reactant). Note that the method (described so far) does not account for the formation of azeotropes.

This paper significantly expands the scope of the mapping method to include non-ideal quaternary systems, with various boiling point orders. The presence of an azeotrope between two compounds with the closest boiling points is significant, as it may correspond to a change of volatility order, i.e. the characteristic relative volatility may be less than 1 . In order to represent the difficulty (or impossibility) of separating the azeotrope-forming mixture, this work sets the relative volatility to 1 .

As in conventional distillation, representative relative volatilities in the shortcut models may not accurately account for the significant nonideality of the systems. Based on this knowledge, this work assumes that the mapping method is unsuitable for quaternary mixtures forming more than one azeotrope between any two components influencing the value of any representative relative volatility. Specifying multiple representative relative volatilities at 1 , due to the presence of azeotropes, might result in over-/underestimation of the applicability of reactive distillation. Therefore, Figure 4 shows that the flowchart rejects systems of this type as unsuitable.

The next step is to characterize the chemical equilibrium constant of the system. As chemical equilibrium is typically temperature dependant, a characteristic temperature needs to be selected; the method is then applied assuming that the equilibrium constant applies throughout the column. This work suggests that the equilibrium constant is calculated at the average boiling points of reactants. The logic for this is that the mixture in the reactive zone of the column will predominantly comprise the reactants, i.e. the boiling point of the mixture will lie between the boiling points of the two pure-component reactants.

A reaction will only achieve a low conversion if its chemical equilibrium constant is small. A low conversion in a reactive distillation column could cause reactants to accumulate in the column, thus promoting the reverse reaction(s) as well as inhibiting separation and/or requiring large reflux ratios to purify the products satisfactorily. Therefore, this work applies the heuristic that reactive distillation is not likely to be an attractive technology for systems with a very low reaction equilibrium constant, i.e. $\mathrm{K}_{\mathrm{eq}}<0.01$ (Shah et al., 2012). In these cases, conventional reaction processes or other types of hybrid processes may be more suitable. On the other hand, systems with a very high chemical equilibrium constant $\left(\mathrm{K}_{\mathrm{eq}}>\right.$ 10) strongly favour high conversion in the reactor, and therefore simultaneous separation in a distillation column may not bring a significant advantage (Shah et al., 2012). In these cases, 
1 conventional reaction-separation-recycle flowsheets are likely to perform satisfactorily. 2 Therefore, the next step of the framework suggests the range of chemical equilibrium constants that is practically relevant for reactive distillation processes, as shown in Figure 4. In spite of that recommendation, evaluating the feasibility of reactive distillation might still be useful for the system with a high chemical equilibrium constant, if a slow kinetically controlled reaction most likely occurs. In real processes, the assumption of reaction equilibrium may be highly unrealistic. For example, parameters that control the reaction and separation performance of a reactive distillation column, relate to reaction kinetics and residence time. The dimensionless Damköhler (Da) number relates key parameters - the reaction rate constant $\left(k_{\mathrm{f}}\right)$, liquid residence time $(\tau)$ and catalyst loading $(\beta)$ :

$$
D a=k_{f} \cdot \beta \cdot \tau
$$

For the calculation of the Damköhler number this method takes into account the liquid residence time per stage, which is actually the ratio of the liquid hold-up per stage to the flow rate per stage. The maximum liquid residence time per stage considered is 120 seconds to enable realistic column designs, i.e. the liquid and catalyst occupy maximum 50\% of the stage hold-up volume. The catalyst loading per stage $(\beta)$ is the volumetric ratio of the amount of catalyst to the liquid hold-up per stage. A large Da number implies fast kinetics, a long liquid residence time, a high liquid hold-up and/or a high catalyst loading, which could benefit the performance of a reactive distillation process.

A higher Da number increases the size of the applicability region for a given reaction, until the applicability region is effectively identical to that when it is assumed that reaction equilibrium is achieved. Overestimation of the liquid residence time, liquid hold-up or catalyst loading, however, may result in an ineffective column operation or even an unfeasible process. Determining appropriate values of those parameters is essential for realistic design of the process. Therefore, the next step in the flowchart uses the ratio of the Da number to the equilibrium constant when applying the generical applicability graphs. At $\mathrm{Da} / \mathrm{Keq} \geq 5$, Muthia et al. (2018a) observed that for a defined generic case with various chemical equilibrium constant values (Keqs $=0.1,1,10)$ the reactive distillation configuration of a kinetically controlled reaction is similar to that of its equilibrium-limited case, in terms of reflux ratio and the number of separation and reactive stages. Additionally, Figure S2 in the 
1 Supporting Information shows that the applicability areas of both equilibrium-limited and

kinetically controlled reactions are identical for two cases representing real reaction systems synthesis of methyl acetate and hydrolysis of methyl lactate. This proves that $\mathrm{Da} / \mathrm{Keq}$ ratios exceeding 5 can be used practically as an initial criterion for initializing the design parameters of reactive distillation column.

The applicability assessment is conducted using pre-prepared graphs of a relevant generic case, i.e. with the same boiling point order and relevant values of the volatilities and equilibrium constant. Further assessment is required to obtain a preliminary economic evaluation of alternative designs. Cost estimation for reactive distillation columns can be obtained by adapting the economic evaluation procedures for conventional distillation, which are explained by Douglas (1988), Seider et al. (2010), Towler and Sinnott (2012). The Supporting Information presents some important equations used to calculating the total annual cost for conventional column.

Our previous work (Muthia et al., 2018b) presents the cost estimation of a reactive distillation process for amyl acetate production, using two assumptions affecting the economic aspect of the column design: 1 ) the cost of reactive trays is $20 \%$ higher than the cost of separation trays because of its non-standard features, and 2) the height of reactive stages is 20 to $30 \%$ larger than that of separation trays to avoid flooding or entrainment because of the presence of catalyst. The study found that the most cost-effective reactive distillation configurations lie close to the boundary line of the applicability graph of the assessed reaction system (i.e., the configurations with the lowest reflux ratios). Furthermore, it suggested that the cost of reactive distillation is more sensitive to the change of reflux ratio than the increase of number of reactive stages; a slight increase of reflux ratio could significantly affect both capital investment and energy requirement.

As described above, the framework presented in Figure 4 provides a systematic approach for screening a quaternary system for its suitability for reactive distillation, for estimating key design parameters, including number of stages, reflux ratio and hold-up on reactive stages, and for preliminary cost estimation of the reactive distillation column. The method is based on some very strongly simplifying assumptions. In our previous work, elements of the method were developed and demonstrated. The next section aims to explore the extent to which the method is useful for screening quaternary mixtures with non-ideal phase equilibrium behaviour. 


\subsection{Case studies: validation of the design framework}

This section presents five case studies for the validation of the proposed framework presented in Figure 4, where these case studies involve non-ideal phase equilibrium behavior, i.e. the formation of homogeneous and heterogeneous azeotropes. The case studies also aim to demonstrate the advantages offered by the method, along with its limitation. The validation steps consist of: (1) preparing the applicability graph of the generic case corresponding to the key parameters of the case study (characteristic relative volatilities and chemical equilibrium constant), and (2) performing rigorous simulations for the case to evaluate the performance predicted by the methodology with that predicted using rigorous simuation.

The case studies belong to groups $\mathrm{I}_{\mathrm{p}}\left(\mathrm{T}_{\mathrm{b}, \mathrm{C}}<\mathrm{T}_{\mathrm{b}, \mathrm{A}}<\mathrm{T}_{\mathrm{b}, \mathrm{B}}<\mathrm{T}_{\mathrm{b}, \mathrm{D}}\right), \mathrm{III}_{\mathrm{p}}\left(\mathrm{T}_{\mathrm{b}, \mathrm{C}}<\mathrm{T}_{\mathrm{b}, \mathrm{A}}<\mathrm{T}_{\mathrm{b}, \mathrm{D}}<\mathrm{T}_{\mathrm{b}, \mathrm{B}}\right)$ and III $_{\mathrm{r}}\left(\mathrm{T}_{\mathrm{b}, \mathrm{A}}<\mathrm{T}_{\mathrm{b}, \mathrm{C}}<\mathrm{T}_{\mathrm{b}, \mathrm{B}}<\mathrm{T}_{\mathrm{b}, \mathrm{D}}\right)$, which offer the promising reactive distillation applications. While reactive distillation might be applicable to group $I_{r}\left(T_{b, A}<T_{b, C}<T_{b, D}<T_{b, B}\right)$, additional equipment for purifying the products is typically needed (Luyben and Yu, 2008; Muthia et al., 2018c). Therefore, reaction systems in class $I_{r}$ are not explored in this work. The case studies are limited to equilibrium-limited reactions. As shown previously (Muthia et al., 2018a), the results for kinetically-controlled reactions are expected to be similar to those for equilibrium-limited reactions.

The suitability of the mapping method to assess quaternary systems is mainly assessed by comparing the predictions from the pre-prepared applicability graphs for generic cases and the rigorous simulation results of corresponding column configurations for real systems. The deviation between the predicted and the actual reflux ratios and numbers of theoretical stages is calculated, to provide a quantitative comparision. Note that: 1) the purpose of the framework is to accelerate the initial assessment of the suitability of reactive distillation for a given reactive system; 2) the purpose of the economic evaluation is to provide a very approximate estimate of costs to assist with decision-making about whether to continue to explore the design option in more detail. Based on our experience of working in and with industrial practitioners, we argue that there is a need for a method that provides qualitative guidance, not necessarily quantitative agreement, to evaluating the RD applicability at an early conceptual design stage in order to support a go/no-go decision.

\subsubsection{Case 1: Methyl acetate synthesis by esterification}

Methyl acetate is widely used as a solvent for producing resins and oils. The production of methyl acetate via esterification is a prime example of successful application of reactive distillation in the chemical industries. Many researchers have used this reaction as a case 
1 study for developing models and design approaches (e.g. Bessling et al., 1998; Kreul et al., 2 1998; Song et al., 1998; Al-Arfaj and Luyben, 2002; Huss et al., 2003; Bangga et al., 2019). 3 This system is selected as a case study for validating our method because it is industrially important and key data are available in the literature. Methyl acetate (C) and water (D) are produced by esterification of methanol (A) and acetic acid (B), as shown in Eq. (2):

$$
\begin{array}{ccccc} 
& \text { Methanol }(\mathbf{A})+\text { acetic acid }(\mathbf{B}) \rightleftharpoons \text { methyl acetate }(\mathbf{C})+\text { water }(\mathbf{D}) \\
\mathrm{T}_{\mathrm{b}}\left({ }^{\circ} \mathrm{C}\right) & 64.7 & 118 & 56.9 & 100
\end{array}
$$

The mixture is in class III $_{\mathrm{p}}$. The UNIQUAC-Hayden-O'Connell property model represents the nonideality of this system (Pöpken et al., 2000). Methyl acetate-methanol and methyl acetatewater form homogeneous binary azeotropes; Table 2 presents their compositions and boiling points. Table S2 in the Supporting Information provides the liquid and equilibrium vapourphase compositions of the feed and products. The representative relative volatilities for 99 mol\% pure products are $\alpha_{\mathrm{CA}}=0.52$ and $\alpha_{\mathrm{DB}}=1.6$ and the feed volatility, $\alpha_{\mathrm{AB}}=6.3$. Following the systematic framework, $\alpha_{\mathrm{CA}}$ is then set as 1 .

Eq. (3) gives the chemical equilibrium expression provided by Popken et al. (2000); $\mathrm{K}_{\mathrm{eq}}=$ 16.3 at the average boiling points of the reactants $\left(91.4^{\circ} \mathrm{C}\right)$.

$$
\ln \left(K_{e q}\right)=-3.82+\frac{2408.65}{T}
$$

Based on the representative key parameters of the case study, applicability graphs of generic cases were prepared for values of $K_{\mathrm{eq}}$ of 10 and 20 , with $\alpha_{\mathrm{CA}}=1.0, \alpha_{\mathrm{AB}}=6.3, \alpha_{\mathrm{DB}}=1.6$, as depicted in Figure 5(a). The shaded area represents the region in which the 'real' boundary line is expected to lie.

Figure 5 shows that the simulation results are in reasonably good agreement with the predictions of the generic applicability graph, in which the concept of using a single reactive distillation is identified as achievable. Figure S2 in the Supporting Information presents applicability graphs for feed stage locations. It is found that locating the feed stages within the reactive zone improves the column performance, as indicated by the increased size of the applicable region. Placing the feeds within the reactive zone supports immediate reaction, therefore lowering the chance of forming an azeotrope between methyl acetate (product C) 
1 and methanol (reactant A). The solid line in Figure 5(a) shows the real boundary line for Case

21 , where both feed stages are within the reactive zone.

3 In spite of the formation of azeotropes, and the assumption in the applicability graph of constant relative volatility, the graph indicates that reactive distillation is applicable. In this system, classified as group III $_{\mathrm{p}}\left(\mathrm{T}_{\mathrm{b}, \mathrm{C}}<\mathrm{T}_{\mathrm{b}, \mathrm{A}}<\mathrm{T}_{\mathrm{b}, \mathrm{D}}<\mathrm{T}_{\mathrm{b}, \mathrm{B}}\right)$, product $\mathrm{C}-$ the lightest compound - is readibly removed as the top product. The high chemical equilibrium constant enables reactant $\mathrm{B}$ - the heaviest compound - to be almost completely consumed before it reaches the stripping section. For example, the composition profile of a column configuration with $\mathrm{NTS}=2 \cdot \mathrm{NTS}_{\min }$ (2 rectifying, 51 reactive and 7 stripping stages) and reflux ratio of 1.8 is given in Figure S3 in the Supporting Information.

\subsubsection{Case 2: 2-Ethylhexyl acrylate production via esterification}

2-Ethylhexyl acrylate (2-EHA) is used in the chemical process industries as a precursor of various homopolymers and copolymers. They are frequently used for the production of coatings, printing inks and adhesives (Komoń et al., 2013). The esterification reaction at the core of the 2-EHA production is shown in Eq. (4).

Acrylic acid $(\mathbf{A})+2$-ethylhexanol $(\mathbf{B}) \rightleftharpoons$ water $(\mathbf{C})+2$-ethylhexyl acrylate (D)

$$
\begin{array}{llll}
\mathrm{T}_{\mathrm{b}}\left({ }^{\circ} \mathrm{C}\right) & 141 & 184 & 100
\end{array}
$$

18

The UNIQUAC-Hayden-O'Connell property model describes the nonideality of the mixtures (Moraru and Bildea, 2018). The mixtures of water/2-ethylhexanol and water/2-EHA compose two heterogeneous binary azeotropes at specific temperatures and compositions, as listed in Table 3. The production of 2-EHA was selected as the second case study because it represents group $\mathrm{I}_{\mathrm{p}}\left(\mathrm{T}_{\mathrm{b}, \mathrm{C}}<\mathrm{T}_{\mathrm{b}, \mathrm{A}}<\mathrm{T}_{\mathrm{b}, \mathrm{B}}<\mathrm{T}_{\mathrm{b}, \mathrm{D}}\right)$ that has the most favored boiling point ranking of quaternary systems. The presence of two azeotropes in this system adds further complexities and challenges compared to the near-ideal quaternary systems in group $I_{p}$ that we have assessed previously (Muthia et al., 2018a, 2019a).

The representative relative volatilities for this case study are $\alpha_{C A}=1.6, \alpha_{A B}=4$ and $\alpha_{B D}=5.3-$ see Table S3 in the Supporting Information for more details. Eq. (5) provides the correlation between the temperature change and chemical equilibrium constant; the representative chemical equilibrium constant is 19.7 , at the average boiling points of reactants $\left(162.5^{\circ} \mathrm{C}\right)$. 


$$
\ln \left(K_{e q}\right)=8.58-\frac{2438.50}{T}
$$

2 Figure 6(a) presents the applicability graphs of the generic cases for values of $\mathrm{K}_{\mathrm{eq}}$ of 15 and 325 , with $\alpha_{C A}=1.6, \alpha_{A B}=4$ and $\alpha_{D B}=5.3$. Those applicability graphs are relevant to the 4 applicability of a single RD column. The shaded area depicts the expected region where the

$$
\begin{array}{ccccc} 
& \text { Acetic acid }(\mathbf{A})+\operatorname{amyl} \text { alcohol }(\mathbf{B}) & \vec{*} \text { water }(\mathbf{C})+\text { amyl acetate }(\mathbf{D}) \\
\mathrm{T}_{\mathrm{b}}\left({ }^{\circ} \mathrm{C}\right) & 118 & 138 & 100 & 147.7
\end{array}
$$

The non-random two-liquid (NRTL) property model describes adequatly the nonideality of this system (Chiang et al., 2002). The Hayden-O'Connell second virial coefficient model was used to account for the dimerization of carboxylic acids in the vapor phase. This system also belongs to group $I_{p}$ (just as case study 2), but it demonstrates further complexity with an 
1 heterogeneous binary, one homogeneous ternary and one heterogeneous ternary azeotropes, as 2 presented in Table 4.

3 The representative relative volatilities for this case study are $\alpha_{C A}=2, \alpha_{A B}=1.7$ and $\alpha_{B D}=1.8-$ 4 see Table S4 in the Supporting Information for details. Eq. (7) shows the formula of the chemical equilibrium constant (Tang et al., 2005); $\mathrm{K}_{\mathrm{eq}}=2$ at the average boiling points of both reactants $\left(128^{\circ} \mathrm{C}\right)$.

$$
\ln \left(K_{e q}\right)=2.63-\frac{777.00}{T}
$$

9 Figure 7(a) gives the applicability graphs of the generic cases for chemical equilibrium constants of 1 and 5, with $\alpha_{C A}=2, \alpha_{A B}=1.7$ and $\alpha_{B D}=1.8$. The predicted boundary line of the applicability area is expected to be within the shaded area and the actual boundary line of the applicability area is indicated by the solid line. The actual and predicted applicability areas include regions on and above their corresponding boundary lines. As observed in case study 2 , due to heterogeneous azeotropes, the simulation result for this case study reveals that there is no applicability graph for a single reactive distillation column. In this reaction, obtaining product $\mathrm{C}$ with the purity $\geq 99 \mathrm{~mol} \%$ is much more difficult than in the previous case study, as the reactive distillation operation is hindered by three potential heterogeneous azeotropes between product $\mathrm{C}$ and other compounds that are composed by high fractions of product $\mathrm{C}$ $\left(x_{C}>0.82\right)$. Instead, the operation of heterogeneous reactive distillation is attainable - see (a) for the actual boundary line of this setup - because a decanter takes advantage of the liquid21 liquid split.

\subsubsection{Case 4: n-Butyl acetate production via esterification}

Butyl acetate is used as a synthetic fruit flavoring in foods (e.g. candy, ice cream, cheese, and baked goods) as well as a high-boiling solvent of moderate polarity. The production of nbutyl acetate is common via the esterification route, as shown in Eq. (8).

$$
\begin{aligned}
& \text { Acetic acid (A) + n-butanol (B) } \rightleftharpoons \text { water }(\text { C })+\text { n-butyl acetate (D) } \\
& \begin{array}{lllll}
\mathrm{T}_{\mathrm{b}}\left({ }^{\circ} \mathrm{C}\right) & 117.9 & 118.8 & 100 & 126.1
\end{array}
\end{aligned}
$$
et al., 1999), and it is associated with the Hayden-O'Connell second virial coefficient model. 
1 Similar to case studies 1 and 2, this system also belongs to group $\mathrm{I}_{\mathrm{p}}$. However, this case study 2 possesses very non-ideal interactions between the compounds. There are six azeotropes

$$
\ln \left(K_{e q}\right)=1.3404+\frac{430.804}{T}
$$

The simulation of the generic cases for $\mathrm{K}_{\mathrm{eq}} \mathrm{s}$ of 10,15 and 20 with $\alpha_{\mathrm{CA}}=1.4, \alpha_{\mathrm{AB}}=1$ and $\alpha_{\mathrm{BD}}=1$ generated no applicability graphs. The finding is acceptable considering the separation difficulty with very strict relative volatilities of compounds.

A set of simulation carried out for the case study confirmed that there is no applicability graph obtained for a single RD column. On the other hand, the simulation result suggested that heterogeneous RD applies to this system. The applicability graph for this setup is presented in Figure 8(a). This finding highlights a mismatch between the prediction based on the generic cases and the results obtained from the rigorous simulation of the case study. The result indicates that the method is unsuitable for the systems with more than one azeotrope between two compounds that represent $99 \mathrm{~mol} \%$ pure products and $50 \mathrm{~mol} \%$ pure reactants because multiple characteristic relative volatilities set as 1, concerning the presence of azeotropes, might underestimate the applicability of reactive distillation. 


$$
\begin{aligned}
& \text { Methyl acetate }(\mathbf{A})+\text { n-butanol }(\mathbf{B}) \gtrless \text { methanol }(\mathbf{C})+\text { n-butyl acetate }(\text { D) } \\
& \mathrm{T}_{\mathrm{b}}\left({ }^{\circ} \mathrm{C}\right) \quad 56.9 \\
& 118.8 \\
& 64.7 \\
& 126.1
\end{aligned}
$$

$$
\ln \left(K_{e q}\right)=0.8158-\frac{267.9}{T}
$$

This reaction was selected as case study because it represents another classification of boiling point rankings in quaternary reactions, namely group III $_{\mathrm{r}}\left(\mathrm{T}_{\mathrm{b}, \mathrm{A}}<\mathrm{T}_{\mathrm{b}, \mathrm{C}}<\mathrm{T}_{\mathrm{b}, \mathrm{B}}<\mathrm{T}_{\mathrm{b}, \mathrm{D}}\right)$. This group may pose a critical challenge for purifying product $\mathrm{C}$ at the top stream, especially when the chemical equilibrium constant is considerably low. The UNIQUAC property model represents the nonideality of the case study (Bożek-Winkler and Gmehling, 2006). There are two homogeneous azeotropes identified between two compounds that represent 99 mol\% pure products, which are methyl acetate/methanol (reactant A / product C) and n-butanol/n-butyl acetate (reactant B / product D), as shown in Table 6. According to the systematic framework, the mapping method should be not suitable for the assessed case study.

For further validation, rigorous simulations were performed for both generic cases and the case study. The representative relative volatilities of this case study for 99 mol\% pure products and 50 mol\% pure reactants are $\alpha_{A C}=3.4, \alpha_{A B}=12$ and $\alpha_{B D}=1.9-$ see Table S6 in the Supporting Information for details. Bożek-Winkler and Gmehling (2006) provide the chemical equilibrium constant expression, as given in Eq. (11). The representative chemical equilibrium constant is 1.08 at the average boiling points of two reactants $\left(87.9^{\circ} \mathrm{C}\right)$.

The applicability graphs of generic cases were prepared for values of $\mathrm{K}_{\mathrm{eq}}$ of 1 and 2 with $\alpha_{A C}=3.4, \alpha A B=12$ and $\alpha_{B D}=1.9$, and the actual boundary line for the case study is expected to be within the shaded area in Figure 8(b). Rigorous simulation of the case study, however, suggested that there is no applicability graph found for a single RD column or any standalone RD setup without additional process equipment, for the targeted purity $\geq 99$ mol\%. Published 
1 literature confirmed that the reactive distillation operation to achieve a high product purity for 2 this reaction is only feasible if it is assisted with membrane technology (Steinigeweg and 3 Gmehling, 2004). The mismatch between the expectation from pre-prepared generic graphs and the simulation results of the case study is caused by an overestimation of the representative relative volatilities of the case study.

\subsection{Analysis of the applicability prediction by the mapping method}

The validation carried out in the previous section highlighted the suitability of the mapping method for non-ideal quaternary systems. Three case studies showed that the method is capable of providing the first screening of reactive distillation designs for high product purity, i.e., $\geq 99$ mol\%. Two case studies showed that the method is unsuitable for the systems with more than one azeotrope that represents 99 mol\% pure products and 50 mol\% pure reactants. In that instance, the use of the mapping method over-/under-estimates the RD designs. An additional assessment was performed to quantify the deviations between the prediction and the actual numbers of theoretical stages based on the generic cases, for the configurations with NTS $=2 \cdot \mathrm{NTS}_{\min }$. The selection of these configurations was only based on our previous knowledge in the classic distillation process. Indeed, other configurations with $R R=1.2 \cdot R R_{\min }$, or with any other considerations, can be evaluated. Using the interpolation technique, the predicted numbers of theoretical stages and reflux ratios of the case studies, at NTS $=2 \cdot$ NTS $_{\min }$, are given in Figure 5(b) for case 1, Figure 6(b) for case 2, Figure 7(b) for case 3. All triangle markers in these figures show the numbers of theoretical stages and all square markers provide the corresponding reflux ratios. Filled triangle and square markers give the actual values obtained from rigorous simulations of the case studies.

The results obtained from the interpolation were compared to the actual numbers of theoretical stages and reflux ratios of the case studies. All deviations were quantified based on the absolute differences between numbers of theoretical stages or reflux ratios over the actual value obtained from the rigorous simulation of the case study, as listed in Table 7. The deviations are reasonably acceptable for case studies 1 and 3, for the assessment at the very early stage of conceptual design level. Large deviations (> 50\%) were obtained for case 2, because of small numbers of theoretical stages and low reflux ratios. Althought percentage wise there are some differences, in terms of absolute numbers the values are very useful for an early industrial assessement of RD applicability. 
1 Overall, the method gives satisfying results regarding the applicability prediction of reactive

2 distillation. The method is useful for engineers in the chemical industries to obtain a go-/no 3 decision prior to performing rigorous simulations of real systems.

\section{Conclusions}

This novel systematic framework proposed here is valuable in assessing the applicability of reactive distillation for non-ideal quaternary systems, using as basis a mapping method that was introduced and developed in our prior work for near-ideal systems (Muthia et al., 2018a, 2019a, 2019b). When reactive distillation is applicable, multiple column configurations and a preliminary economic evaluation are obtained for an assessed chemical system. The sequential steps in the workflow consist of the recognition of the group of boiling point rankings, the calculation of the key relative volatilities and chemical equilibrium constant of the real system to select the most relevant pre-prepared applicability graphs of generic cases and the preliminary economic evaluation. For kinetically controlled reactions, the determination of catalyst loading, liquid residence time or liquid hold-up is based on an initial criterion of $\mathrm{Da} / \mathrm{K}_{\mathrm{eq}} \geq 5$, so that one can estimate the values of those design parameters to obtain the optimum RD design.

The use of the systematic framework has been successfully validated using five case studies that represent different groups of boiling point ranking in quaternary systems, and have distinctive separation complexities due to azeotropes. The boiling point rankings give a significant effect on the RD performance. As shown in case studies 1-4, having a product as the lightest compound is favored, so the product can be easily collected at the top stream with high purity. The given case studies proved that the applicability of reactive distillation is significantly affected by the nonideality of the systems which is indicated by the number and the types of azeotropes present. Reactive distillation with a decanter might be considered if heterogeneous azeotropes exist between the lightest product and the other compounds. The validation of the approach using case studies 1-3 showed that the framework is suitable also for complex systems with only one azeotrope between two compounds that represent 99 mol\% pure products and $50 \mathrm{~mol} \%$ pure reactants. Representative relative volatilities calculated for $99 \mathrm{~mol} \%$ pure products and $50 \mathrm{~mol} \%$ pure reactants correspond to the desired product compositions and the equimolar feed of reactants. The proposed approach is capable of predicting the applicability of reactive distillation by disregarding the types of column setup, for instance, if a decanter is needed to overcome heterogeneous azeotropes. By only referring to some basic parameters, the systematic framework allows engineers in the 
1 chemical industries to reduce the number of rigorous simulations required in the early

2 conceptual design stage.

3 The validation of the approach using case studies 4 and 5 showed that the framework is

4 unsuitable for strongly non-ideal systems with multiple azeotropes present between two components affecting representative relative volatilities. The limitation of the proposed method is analogous to that of shortcut methods for conventional distillation (such as FenskeUnderwoord-Gilliland), where assumed constant relative volatilities are unable to provide accurate initial column designs for the separation of strongly non-ideal systems.

\section{Acknowledgment}

11 RM thankfully acknowledges Indonesia Endowment Fund for Education (LPDP) for funding 12 her doctoral studies. AAK gratefully acknowledges the Royal Society Wolfson Research 13 Merit Award.

\section{Nomenclature}

$17 K_{e q} \quad$ chemical equilibrium constant [-]

18 NTS number of theoretical stages [-]

$19 N T S_{\min } \quad$ minimum number of theoretical stages [-]

$20 \quad R R \quad$ reflux ratio $[\mathrm{mol} / \mathrm{mol}]$

$21 \quad R R_{\min } \quad$ minimum reflux ratio $[\mathrm{mol} / \mathrm{mol}]$

$22 T_{b} \quad$ boiling point temperature $\left[{ }^{\circ} \mathrm{C}\right]$

$23 x_{i} \quad$ mol fraction of compound $\mathrm{i}$

$24 \quad \alpha_{i j} \quad$ relative volatility between compounds $\mathrm{i}$ and $\mathrm{j}[-]$

$25 \Delta \mathrm{H}_{\mathrm{r}}^{\circ} \quad$ heat of reaction $[\mathrm{kJ} / \mathrm{mol}]$

\section{References}

29 1. Amte, V., Nistala, S.H., Mahajani, S.M., Malik, R.K., 2013. Optimization based conceptual design of reactive distillation for selectivity engineering. Comput. Chem. Eng. 48, 209-217.

2. Al-Arfaj, M.A., Luyben, W.L., 2002. Comparative control study of ideal and methyl acetate reactive distillation. Chem. Eng. Sci. 57, 5039-5050.

3. Almeida-Rivera, C.P., Swinkels, P.L.J., Grievink, J., 2004. Designing reactive distillation 
processes: present and future. Comput. Chem. Eng. 28, 1997-2020.

4. Bangga, G., Novita, F.J., Lee, H.-Y., 2019. Evolutional computational fluid dynamics analyses of reactive distillation columns for methyl acetate production process. Chem. Eng. Process. Process Intensif. 135, 42-52.

5. Barbosa, D., Doherty, M.F., 1988a. Design and minimum-reflux calculations for singlefeed multicomponent reactive distillation columns. Chem. Eng. Sci. 43, 1523-1537.

6. Barbosa, D., Doherty, M.F., 1988b. The simple distillation of homogeneous reactive mixtures. Chem. Eng. Sci. 43, 541-550.

7. Bessling, B., Löning, J.-M., Ohligschläger, A., Schembecker, G., Sundmacher, K., 1998. Investigations on the synthesis of methyl acetate in a heterogeneous reactive distillation process. Chem. Eng. Technol. 21, 393-400.

8. Bożek-Winkler, E., Gmehling, J., 2006. Transesterification of methyl acetate and nbutanol catalyzed by Amberlyst 15. Ind. Eng. Chem. Res. 45, 6648-6654.

9. Charpentier, J.-C., 2007. In the frame of globalization and sustainability, process intensification, a path to the future of chemical and process engineering (molecules into money). Chem. Eng. J. 134, 84-92.

10. Chen, C.-S., Yu, C.-C., 2008. Effects of relative volatility ranking on design and control of reactive distillation systems with ternary decomposition reactions. Ind. Eng. Chem. Res. 47, 4830-4844.

11. Chen, F., Huss, R.S., Malone, M.F., Doherty, M.F., 2000. Simulation of kinetic effects in reactive distillation. Comput. Chem. Eng. 24, 2457-2472.

12. Chiang, S.-F., Kuo, C.-L., Yu, C.-C., Wong, D.S.H., 2002. Design alternatives for the amyl acetate process: Coupled reactor/column and reactive distillation. Ind. Eng. Chem. Res. 41, 3233-3246.

13. Chiu, C.-W., Dasari, M.A., Suppes, G.J., Sutterlin, W.R., 2006. Dehydration of glycerol to acetol via catalytic reactive distillation. AIChE J. 52, 3543-3548.

14. Damartzis, T., Seferlis, P., 2010. Optimal design of staged three-phase reactive distillation columns using nonequilibrium and orthogonal collocation models. Ind. Eng. Chem. Res. 49, 3275-3285.

15. Douglas J.M., 1988. Cost Data. In: B.J. Clark and J.W. Bradley (Eds.), Conceptual design of chemical processes. McGraw-Hill Book, USA, pp. 572-575.

16. Gangadwala, J., Mankar, S., Mahajani, S., 2003. Esterification of acetic acid with butanol in the presence of ion-exchange resins as catalysts. Ind. Eng. Chem. Res. 42, 2146-2155.

17. Giessler, S., Danilov, R.Y., Pisarenko, R.Y., Serafimov, L.A., Hasebe, S., Hashimoto, I., 
1998. Feasibility study of reactive distillation using the analysis of the statics. Ind. Eng. Chem. Res. 37, 4375-4382.

18. Götze, L., Bailer, O., Moritz, P., von Scala, C., 2001. Reactive distillation with KATAPAK®. Catal. Today. 69, 201-208.

19. Harmsen, G.J., 2007. Reactive distillation: The front-runner of industrial process intensification: A full review of commercial applications, research, scale-up, design and operation. Chem. Eng. Process. Process Intensif. 46, 774-780.

20. Hiwale, R.S., Bhate, N.V., Mahajan, Y.S., Mahajani, S.M., 2004. Industrial applications of reactive distillation: Recent trends. Int. J. Chem. React. Eng. 2.

21. Huss, R.S., Chen, F., Malone, M.F., Doherty, M.F., 2003. Reactive distillation for methyl acetate production. Comput. Chem. Eng. 27, 1855-1866.

22. Jantharasuk, A., Gani, R., Górak, A., Assabumrungrat, S., 2011. Methodology for design and analysis of reactive distillation involving multielement systems. Chem. Eng. Res. Des. 89, 1295-1307.

23. Keller, T., Holtbruegge, J., Górak, A., 2012. Transesterification of dimethyl carbonate with ethanol in a pilot-scale reactive distillation column. Chem. Eng. J. 180, 309-322.

24. Khan, M.A., Adewuyi, Y.G., 2019. Techno-economic modeling and optimization of catalytic reactive distillation for the esterification reactions in bio-oil upgradation. Chem. Eng. Res. Des. 148, 86-101.

25. Kiss, A. A.; Process intensification: Industrial applications, in Segovia-Hernandez, J. G.; Bonilla-Petriciolet A. (Eds); Process intensification in chemical engineering: Design, optimization and control, Springer International Publishing, 2016.

26. Kiss, A. A.; Process intensification for reactive distillation, in Rong, B-G. (Ed); Process synthesis and process intensification: Methodological approaches, de Gruyter, 2017.

27. Kiss, A. A.; Novel catalytic reactive distillation processes for a sustainable chemical industry, Top. Catal., 2019, Article in press, DOI: 10.1007/s11244-018-1052-9

28. Kiss, A.A., Dimian, A.C., Rothenberg, G., 2008. Biodiesel by catalytic reactive distillation powered by metal oxides. Energ. Fuel. 22, 598-604.

29. Kiss, A.A., Jobson, M., Gao, X., 2019. Reactive distillation: Stepping up to the next level of process intensification. Ind. Eng. Chem. Res. 58, 5909-5918.

30. Komoń, T., Niewiadomski, P., Oracz, P., Jamróz, M.E., 2013. Esterification of acrylic acid with 2-ethylhexan-1-ol: Thermodynamic and kinetic study. Appl. Catal. A-Gen. 451, 127-136.

31. Kreul, L.U., Górak, A., Dittrich, C., Barton, P.I., 1998. Dynamic catalytic distillation: 
Advanced simulation and experimental validation. Comput. Chem. Eng. 22, S371-S378.

32. Lee, J.W., Hauan, S., Westerberg, A.W., 2000. Graphical methods for reaction distribution in a reactive distillation column. AIChE J. 46, 1218-1233.

33. Li, H., Meng, Y., Li, X., Gao, X., 2016. A fixed point methodology for the design of reactive distillation column. Chem. Eng. Res. Des. 111, 479-491.

34. Li, P., Huang, K., Lin, Q., 2012. A generalized method for the synthesis and design of reactive distillation columns. Chem. Eng. Res. Des. 90, 173-184.

35. Luyben, W.L., Yu, C.-C., 2008. Reactive distillation design and control. John Wiley \& Sons, Inc., USA.

36. Moraru, M.D., Bildea, C.S., 2018. Reaction-Separation-Recycle processes for 2ethylhexyl acrylate production: Design, control, and economic evaluation. Ind. Eng. Chem. Res. 57, 2609-2627.

37. Muthia, R., Jobson, M., Kiss, A.A., 2019a. Innovative mapping method for screening reactive distillation designs. Comput. Aided Chem. Eng. 46, 739-744.

38. Muthia, R., Reijneveld, A.G.T., van der Ham, A.G.J., ten Kate, A.J.B., Bargeman, G., Kersten, S.R.A., Kiss, A.A., 2018a. Novel method for mapping the applicability of reactive distillation. Chem. Eng. Process. Process Intensif. 128, 263-275.

39. Muthia, R., van der Ham, A.G.J., Jobson, M., Kiss, A.A., 2019b. Effect of boiling point rankings and feed locations on the applicability of reactive distillation to quaternary systems. Chem. Eng. Res. Des. 145, 184-193.

40. Muthia, R., van der Ham, A.G.J., Kiss, A.A., 2018b. A novel method for determining the optimal operating points of reactive distillation processes. Chem. Eng. Trans. 69, 595600 .

41. Muthia, R., van der Ham, A.G.J., Kiss, A.A., 2018c. Preliminary economic ranking of reactive distillation processes using a navigation method. Comput. Aided Chem. Eng. 43, 827-832.

42. Pöpken, T., Götze, L., Gmehling, J., 2000. Reaction kinetics and chemical equilibrium of homogeneously and heterogeneously catalyzed acetic acid esterification with methanol and methyl acetate hydrolysis. Ind. Eng. Chem. Res. 39, 2601-2611.

43. Segovia-Hernández, J.G., Hernández, S., Bonilla Petriciolet, A., 2015. Reactive distillation: A review of optimal design using deterministic and stochastic techniques. Chem. Eng. Process. Process Intensif. 97, 134-143.

44. Seider, W.D., Seader, J.D., Lewin, D.R., Widagdo, S., 2010. Product and process design principles: Synthesis, analysis, and design. John Wiley and Sons, Inc., USA. 
45. Shah, M., Kiss, A.A., Zondervan, E., de Haan, A.B., 2012. A systematic framework for the feasibility and technical evaluation of reactive distillation processes. Chem. Eng. Process. Process Intensif. 60, 55-64.

46. Sharma, M.M., Mahajani, S.M., 2003. Industrial application of reactive distillation. In: Sundmacher, K., Kienle, A. (Eds.), Reactive distillation: Status and future directions. John Wiley \& Sons, Germany, pp. 3-26.

47. Sharma, N., Singh, K., 2010. Control of reactive distillation column: A review. Int. J. Chem. React. Eng. 8.

48. Smith, R., 2016. Chemical process design and integration. John Wiley \& Sons Ltd., United Kingdom.

49. Sneesby, M.G., Tadé, M.O., Datta, R., Smith, T.N., 1997. ETBE Synthesis via reactive distillation. 2. Dynamic simulation and control aspects. Ind. Eng. Chem. Res. 36, 18701881 .

50. Song, W., Venimadhavan, G., Manning, J.M., Malone, M.F., Doherty, M.F., 1998. Measurement of residue curve maps and heterogeneous kinetics in methyl acetate synthesis. Ind. Eng. Chem. Res. 37, 1917-1928.

51. Stankiewicz, A.I., Moulijn, J.A., 2000. Process intensification: Transforming chemical engineering. Chem. Eng. Prog., 22-34.

52. Steinigeweg, S., Gmehling, J., 2004. Transesterification processes by combination of reactive distillation and pervaporation. Chem. Eng. and Process. Process Intensif. 43, 447-456.

53. Subawalla, H., González, J.C., Seibert, A.F., Fair, J.R., 1997. Capacity and efficiency of reactive distillation bale packing: Modeling and experimental validation. Ind. Eng. Chem. Res. 36, 3821-3832.

54. Tang, Y.-T., Chen, Y.-W., Huang, H.-P., Yu, C.-C., Hung, S.-B., Lee, M.-J., 2005. Design of reactive distillations for acetic acid esterification. AIChE J. 51, 1683-1699.

55. Taylor, R., Krishna, R., 2000. Modelling reactive distillation. Chem. Eng. Sci. 55, 51835229.

56. Thery, R., Meyer, X.M., Joulia, X., Meyer, M., 2005. Preliminary design of reactive distillation columns. Chem. Eng. Res. Des. 83, 379-400.

57. Towler, G., Sinnott, R., 2012. Chemical engineering design: Principles, practice and economics of plant and process design. Butterworth-Heinemann, USA.

58. Tuchlenski, A., Beckmann, A., Reusch, D., Düssel, R., Weidlich, U., Janowsky, R., 2001. Reactive distillation - industrial applications, process design \& scale-up. Chem. Eng. Sci. 
$56,387-394$.

2

59. Ung, S., Doherty, M.F., 1995. Synthesis of reactive distillation systems with multiple equilibrium chemical reactions. Ind. Eng. Chem. Res. 34, 2555-2565.

60. Urselmann, M., Barkmann, S., Sand, G., Engell, S., 2011. Optimization-based design of reactive distillation columns using a memetic algorithm. Comput. Chem. Eng. 35, 787805.

61. Venimadhavan, G., Malone, M.F., Doherty, M.F., 1999. A novel distillate policy for batch reactive distillation with application to the production of butyl acetate. Ind. Eng. Chem. Res. 38, 714-722.

62. Wierschem, M., Górak, A., 2018. Reactive distillation. Reference Module in Chemistry, Molecular Sciences and Chemical Engineering. 1-10. 


\section{Table}

2 Table 1. Summary of characteristic volatilities for quaternary mixtures of groups I and III 3

\begin{tabular}{cccc}
\hline Group & Boiling point order & Volatility order & Characteristic product volatilities \\
\hline $\mathrm{I}_{\mathrm{p}}$ & $\mathrm{T}_{\mathrm{b}, \mathrm{C}}<\mathrm{T}_{\mathrm{b}, \mathrm{A}}<\mathrm{T}_{\mathrm{b}, \mathrm{B}}<\mathrm{T}_{\mathrm{b}, \mathrm{D}}$ & $\mathrm{C}>\mathrm{A}>\mathrm{B}>\mathrm{D}$ & $\begin{array}{l}\text { Distillate: } \alpha_{\mathrm{CA}}(99 \% \mathrm{C}, 1 \% \mathrm{~A}) \\
\text { Bottoms: } \alpha_{\mathrm{BD}}(1 \% \mathrm{~B}, 99 \% \mathrm{D})\end{array}$ \\
\hline $\mathrm{III}_{\mathrm{p}}$ & $\mathrm{T}_{\mathrm{b}, \mathrm{C}}<\mathrm{T}_{\mathrm{b}, \mathrm{A}}<\mathrm{T}_{\mathrm{b}, \mathrm{D}}<\mathrm{T}_{\mathrm{b}, \mathrm{B}}$ & $\mathrm{C}>\mathrm{A}>\mathrm{D}>\mathrm{B}$ & $\begin{array}{l}\text { Distillate: } \alpha_{\mathrm{CA}}(99 \% \mathrm{C}, 1 \% \mathrm{~A}) \\
\text { Bottoms: } \alpha_{\mathrm{DB}}(99 \% \mathrm{D}, 1 \% \mathrm{~B})\end{array}$ \\
\hline $\mathrm{III}_{\mathrm{r}}$ & $\mathrm{T}_{\mathrm{b}, \mathrm{A}}<\mathrm{T}_{\mathrm{b}, \mathrm{C}}<\mathrm{T}_{\mathrm{b}, \mathrm{B}}<\mathrm{T}_{\mathrm{b}, \mathrm{D}}$ & $\mathrm{A}>\mathrm{C}>\mathrm{B}>\mathrm{D}$ & $\begin{array}{l}\text { Distillate: } \alpha_{\mathrm{AC}}(1 \% \mathrm{~A}, 99 \% \mathrm{C}) \\
\text { Bottoms: } \alpha_{\mathrm{BD}}(1 \% \mathrm{~B}, 99 \% \mathrm{D})\end{array}$ \\
\hline $\mathrm{I}_{\mathrm{r}}$ & $\mathrm{T}_{\mathrm{b}, \mathrm{A}}<\mathrm{T}_{\mathrm{b}, \mathrm{C}}<\mathrm{T}_{\mathrm{b}, \mathrm{D}}<\mathrm{T}_{\mathrm{b}, \mathrm{B}}$ & $\mathrm{A}>\mathrm{C}>\mathrm{D}>\mathrm{B}$ & $\begin{array}{l}\text { Distillate: } \alpha_{\mathrm{AC}}(1 \% \mathrm{~A}, 99 \% \mathrm{C}) \\
\text { Bottoms: } \alpha_{\mathrm{DB}}(99 \% \mathrm{D}, 1 \% \mathrm{~B})\end{array}$ \\
\hline
\end{tabular}

4

5

6

7

8

9

10

11

12

13

14

15

16

17

18

19

20

\begin{tabular}{ccccccc}
\hline No. & Type & $\begin{array}{c}\text { Boiling point } \\
\left({ }^{\circ} \mathrm{C}\right)\end{array}$ & $\begin{array}{c}\text { Methanol } \\
(\mathrm{A})\end{array}$ & $\begin{array}{c}\text { Acetic } \\
\text { acid (B) }\end{array}$ & $\begin{array}{c}\text { Methyl } \\
\text { acetate (C) }\end{array}$ & Water (D) \\
\hline 1 & Homogeneous & 53.7 & 0.341 & - & 0.659 & - \\
\hline 2 & Homogeneous & 56.4 & - & - & 0.890 & 0.110
\end{tabular}

Table 2. Molar composition of the axeotropes and corresponding boiling points in the system containing methanol, acetic acid, methyl acetate and water at 1 atm 
2 Table 3. Molar composition of the axeotropes and corresponding in the system containing acrylic acid, 2-ethylhexanol, water and 2-ethylhexyl acrylate at $1 \mathrm{~atm}$

4

\begin{tabular}{ccccccc}
\hline No. & Type & $\begin{array}{c}\text { Boiling } \\
\text { point } \\
\left({ }^{\circ} \mathrm{C}\right)\end{array}$ & $\begin{array}{c}\text { Acrylic } \\
\text { acid (A) }\end{array}$ & $\begin{array}{c}\text { 2-ethylhexanol } \\
(\mathrm{B})\end{array}$ & $\begin{array}{c}\text { Water } \\
(\mathrm{C})\end{array}$ & $\begin{array}{c}\text { 2-ethylhexyl } \\
\text { acrylate (D) }\end{array}$ \\
\hline 1 & Heterogeneous & 99.1 & - & 0.032 & 0.968 & - \\
\hline 2 & Heterogeneous & 99.6 & - & - & 0.984 & 0.016 \\
\hline
\end{tabular}

5

6

7

8

9

10

11

12

13

14

15

16

17

18

Table 4. Molar composition of the axeotropes and corresponding in the system containing

19

\begin{tabular}{ccccccc}
\hline No. & Type & $\begin{array}{c}\text { Boiling } \\
\text { point } \\
\left({ }^{\circ} \mathrm{C}\right)\end{array}$ & $\begin{array}{c}\text { Acetic } \\
\text { acid (A) }\end{array}$ & $\begin{array}{c}\text { Amyl } \\
\text { alcohol (B) }\end{array}$ & Water (C) & $\begin{array}{c}\text { Amyl } \\
\text { acetate (D) }\end{array}$ \\
\hline 1 & Heterogeneous & 94.7 & - & 0.044 & 0.823 & 0.133 \\
\hline 2 & Heterogeneous & 94.9 & - & - & 0.830 & 0.170 \\
\hline 3 & Heterogeneous & 95.9 & - & 0.148 & 0.852 & - \\
\hline 4 & Homogeneous & 139.9 & 0.218 & 0.585 & - & 0.197 \\
\hline 5 & Homogeneous & 140.3 & 0.260 & 0.740 & - & - \\
\hline
\end{tabular}
acetic acid, amyl alcohol, water and amyl acetate at 1 atm 
2 Table 5. Molar composition of the axeotropes and corresponding in the system containing methyl acetate, n-butanol, methanol and n-butyl acetate at 1 atm

4

\begin{tabular}{ccccccc}
\hline No. & Type & $\begin{array}{c}\text { Boiling } \\
\text { point } \\
\left({ }^{\circ} \mathrm{C}\right)\end{array}$ & $\begin{array}{c}\text { Acetic } \\
\text { acid (A) }\end{array}$ & $\begin{array}{c}\text { n-Butanol } \\
(\mathrm{B})\end{array}$ & Water (C) & $\begin{array}{c}\text { n-Butyl } \\
\text { acetate (D) }\end{array}$ \\
\hline 1 & Heterogeneous & 90.1 & - & 0.107 & 0.690 & 0.203 \\
\hline 2 & Heterogeneous & 90.9 & - & - & 0.715 & 0.285 \\
\hline 3 & Heterogeneous & 92.7 & - & 0.243 & 0.757 & - \\
\hline 4 & Homogeneous & 114.7 & - & 0.647 & - & 0.353 \\
\hline 5 & Homogeneous & 120.8 & 0.537 & 0.150 & - & 0.313 \\
\hline 6 & Homogeneous & 123.4 & 0.537 & 0.463 & - & -
\end{tabular}

5

6

7

8

9

10

11

12

13

14

15

16

17

Table 6. Molar composition of the axeotropes and corresponding in the system containing methyl acetate, n-butanol, methanol and n-butyl acetate at 1 atm

\begin{tabular}{ccccccc}
\hline No. & Type & $\begin{array}{c}\text { Boiling } \\
\text { point } \\
\left({ }^{\circ} \mathrm{C}\right)\end{array}$ & $\begin{array}{c}\text { Methyl } \\
\text { acetate (A) }\end{array}$ & n-Butanol (B) & $\begin{array}{c}\text { Methanol } \\
\text { (C) }\end{array}$ & $\begin{array}{c}\text { n-Butyl } \\
\text { acetate (D) }\end{array}$ \\
\hline 1 & Homogeneous & 53.7 & 0.659 & - & 0.341 & - \\
\hline 2 & Homogeneous & 116.9 & - & 0.780 & - & 0.220 \\
\hline
\end{tabular}

19 
1 Table 7. Comparison of predicted and actual numbers of theoretical stages and reflux ratios 2

\begin{tabular}{|c|c|c|c|c|c|c|c|}
\hline \multirow[t]{2}{*}{ No. } & \multirow[t]{2}{*}{ Case studies } & \multicolumn{3}{|c|}{$\begin{array}{c}\text { Number of theoretical } \\
\text { stages / [-] }\end{array}$} & \multicolumn{3}{|c|}{ Reflux ratio / [mol/mol] } \\
\hline & & Predicted & Actual & Deviation & Predicted & Actual & Deviation \\
\hline 1 & Case 1 & 40 & 60 & $33 \%$ & 1.94 & 1.63 & $19 \%$ \\
\hline 2 & Case 2 & 15 & 8 & $88 \%$ & 0.80 & 0.39 & $105 \%$ \\
\hline 3 & Case 3 & 29 & 20 & $45 \%$ & 1.90 & 1.54 & $23 \%$ \\
\hline
\end{tabular}

3 
$1 \quad$ Figure captions (auto-updated)

2 Figure 1. Schematic representation of (a) a single reactive distillation column and (b) a 3 heterogeneous reactive distillation column.

4 Figure 2. (a) An illustrative applicability graph of reactive distillation and (b) an illustrative prediction of the applicability of reactive distillation to a reaction system, based on generic cases - the actual boundary line is predicted to be within the shaded area.

7 Figure 3. Methodology developed for the generation of the applicability graphs of reactive 8 distillation, the validation of the mapping method and the use of the method by end-users.

9 Figure 4. Systematic framework for assessing the applicability of reactive distillation. Figure 5. Case 1 - methyl acetate production via esterification (a) The predicted boundary line of the RD applicability within the shaded area and the actual boundary line of the RD applicability indicated by the solid line; (b) Reflux ratio and the number of theoretical stages: solid points $=$ estimate; open points $=$ rigorous simulation results.

14 Figure 6. Case 2 - 2-ethylhexyl acetate synthesis via esterification (a) The predicted boundary 15 line of the RD applicability within the shaded area and the actual boundary line of the RD 16 applicability indicated by the solid line; (b) Reflux ratio and the number of theoretical stages: solid points $=$ estimate; open points $=$ rigorous simulation results. Figure 7. Case 3 - amyl acetate production via esterification (a) The predicted boundary line of the RD applicability within the shaded area and the actual boundary line of the RD applicability indicated by the solid line; (b) Reflux ratio and the number of theoretical stages:

21 solid points = estimate; open points = rigorous simulation results.

22 Figure 8. (a) The actual boundary line of the applicability area of case 4 - butyl acetate synthesis via esterification - for a heterogeneous reactive distillation setup and (b) the predicted boundary line of the applicability area of case 5 - transesterification of methyl acetate and butanol - within the shaded area. 


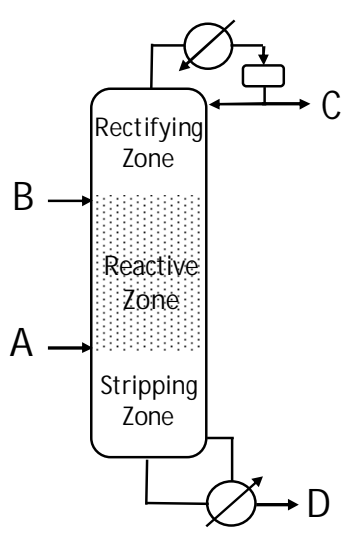

(a)

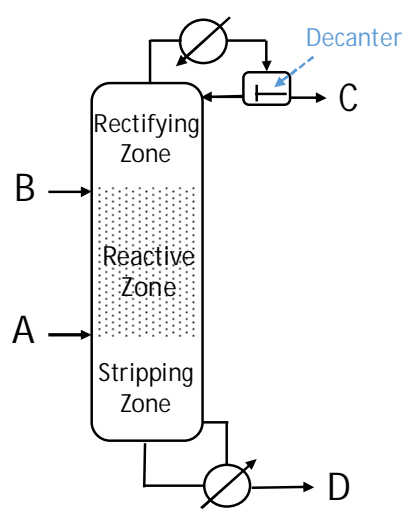

(b)

Figure 1. Schematic representation of (a) a single reactive distillation column and (b) a heterogeneous reactive distillation column.

(a)

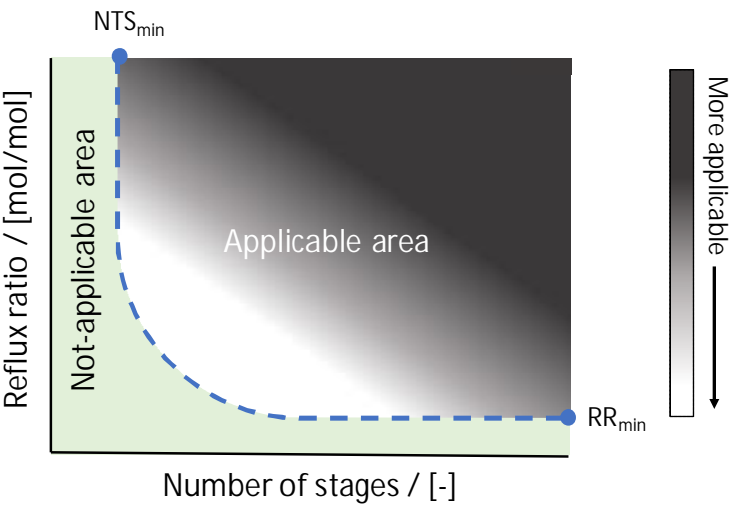

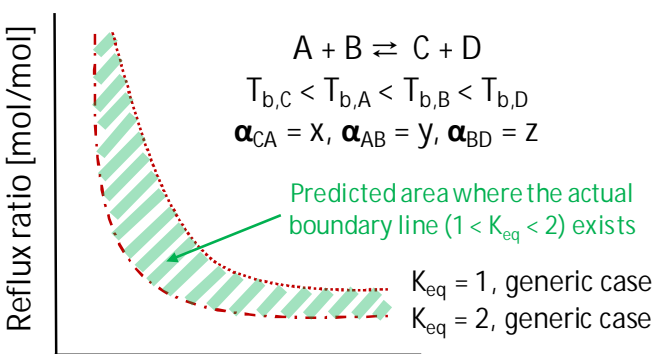

Number of stages [-]

(b)

17 Figure 2. (a) An illustrative applicability graph of reactive distillation and (b) an illustrative prediction of the applicability of reactive distillation to a reaction system, based on generic cases - the actual boundary line is predicted to be within the shaded area. 


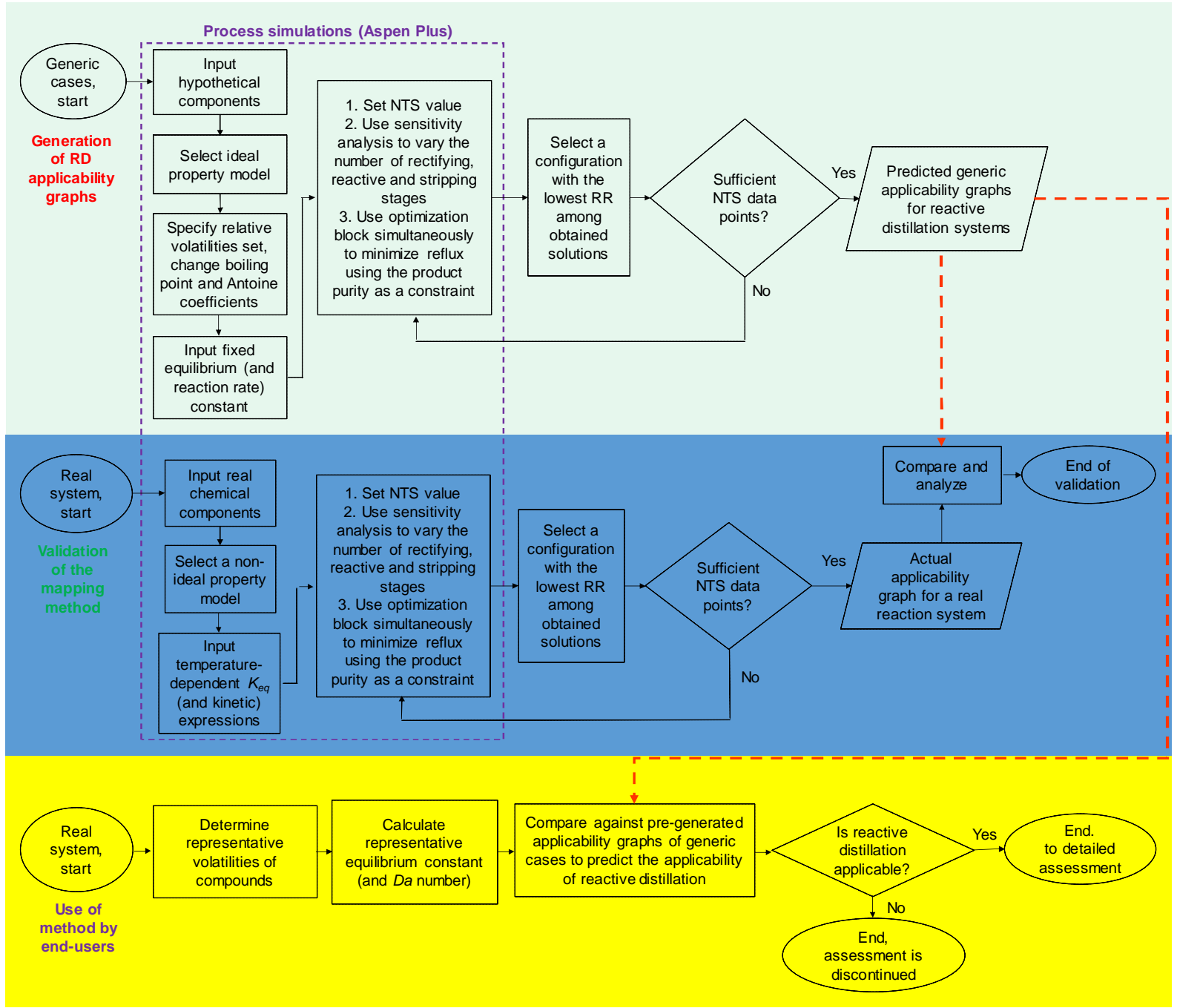

Figure 3. Methodology developed for the generation of the applicability graphs of reactive distillation, the validation of the mapping method and the use of the method by end-users. 


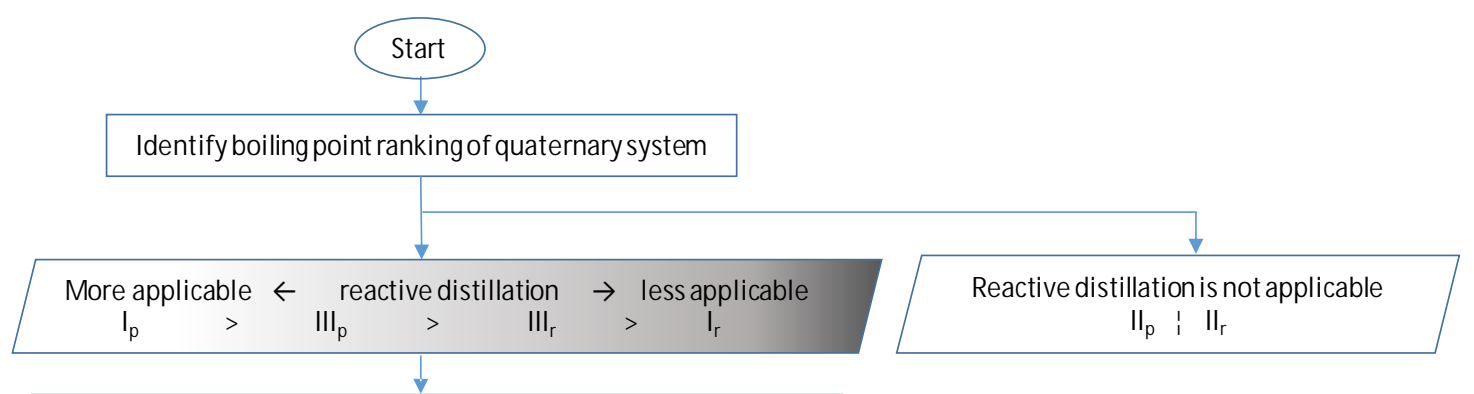

Calculate representative relative volatilities ( $\alpha$ ) of compounds for $99 \mathrm{~mol} \%$ pure products and $50 \mathrm{~mol} \%$ pure feed.

$\alpha$ isfixed at 1 when the actual $\alpha<1$ because of azeotrope

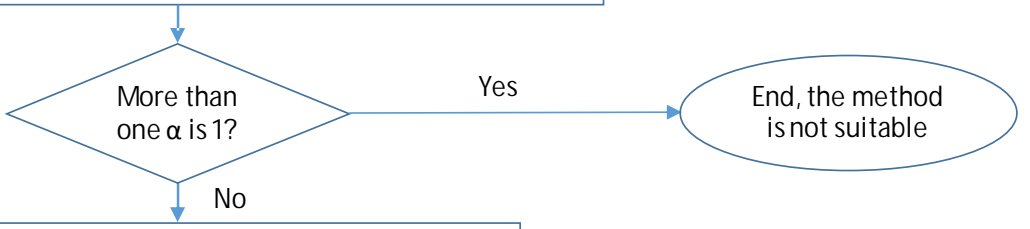

Calculate representativechemical equilibrium constant at the average boiling points of reactants

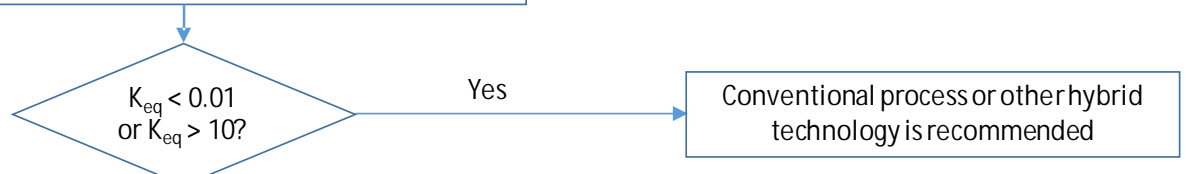

\begin{tabular}{|ccc|}
\hline & $\begin{array}{c}\text { Reactive distillation is } \\
\text { technically possibleand may } \\
\text { be commercially attractive }\end{array}$ & $\begin{array}{c}\text { Reactive distillation istechnically } \\
\text { possible and economically } \\
\text { attractive (Shah, etal., 2012) }\end{array}$ \\
\hline
\end{tabular}

Determine catalyst loading and liquid residence time or hold-up Initial criterion: $\frac{D a}{K e q}=5$

Use pre-prepared applicability graphs of generic cases in the mapping method to predict the applicability area of the assessed real system
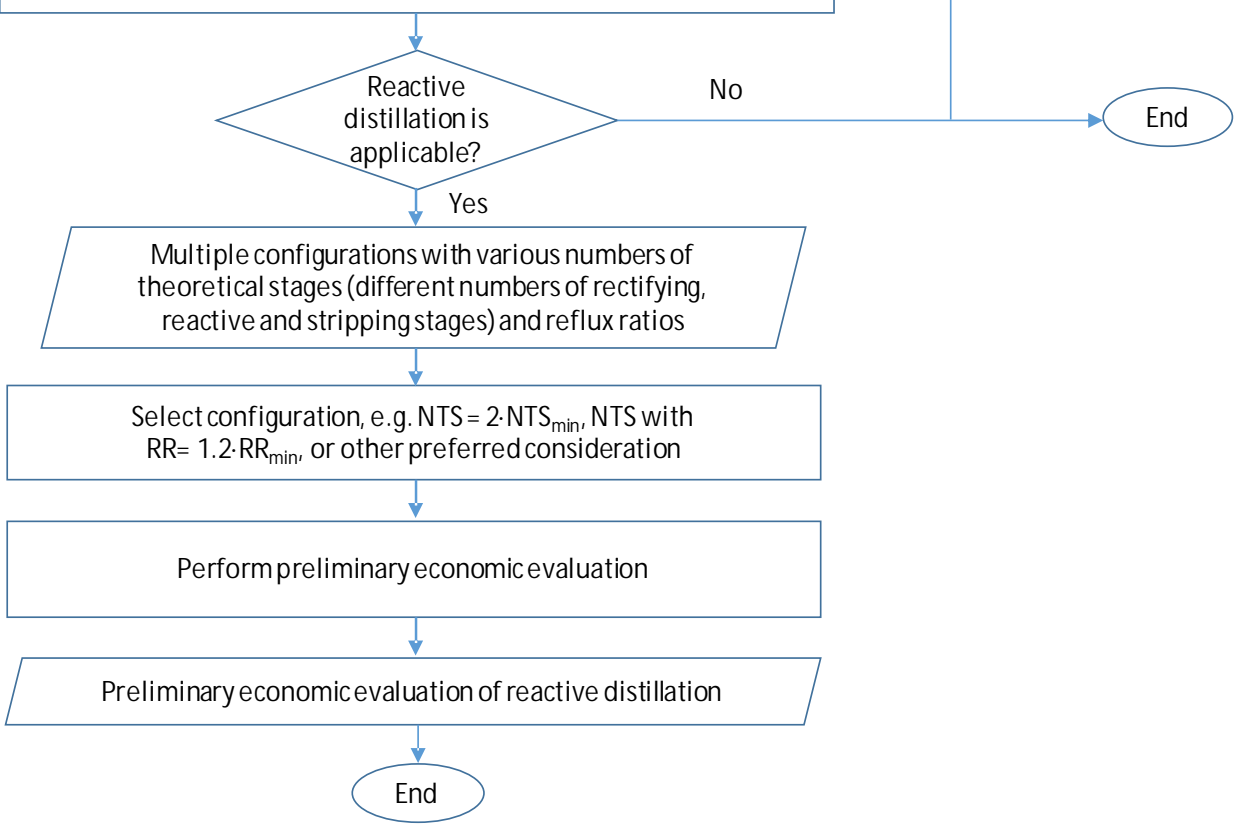

Figure 4. Systematic framework for assessing the applicability of reactive distillation. 


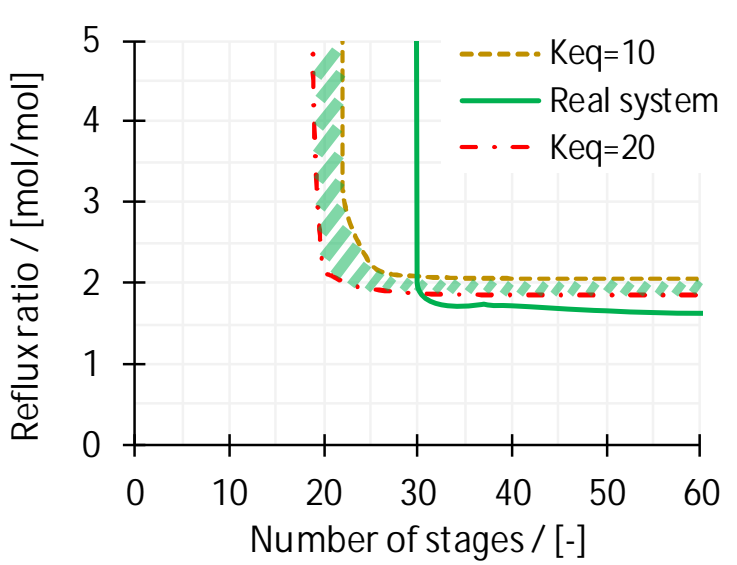

(a)

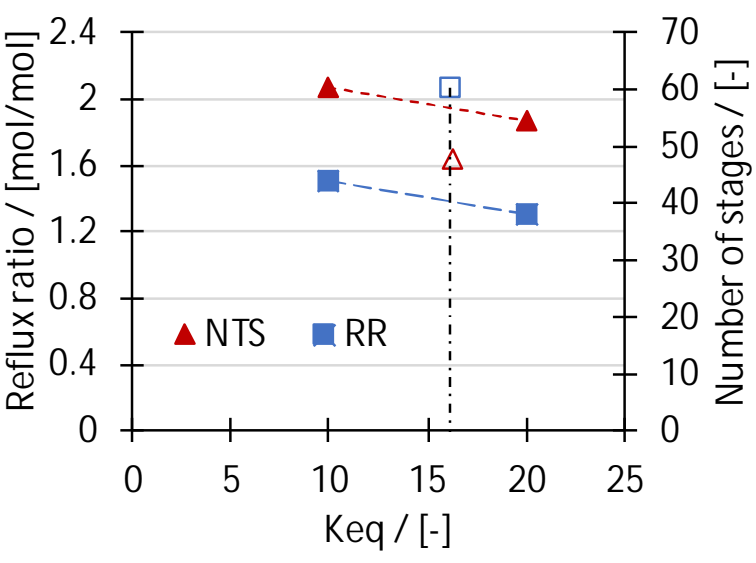

(b)

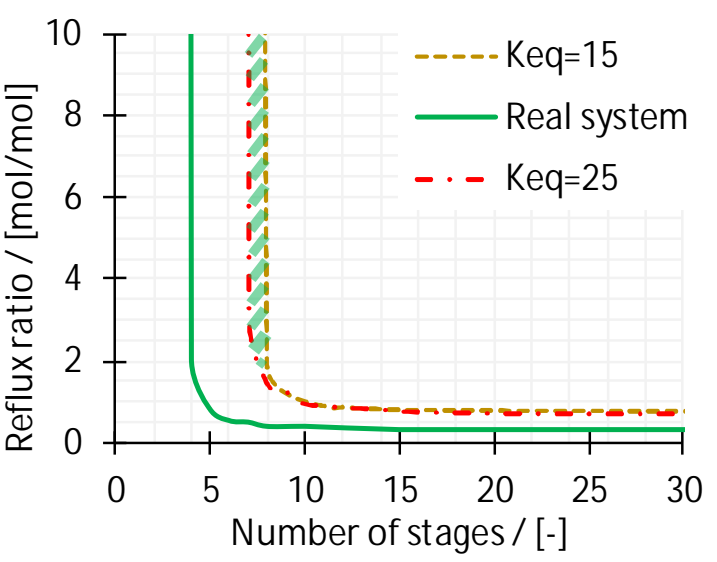

(a)

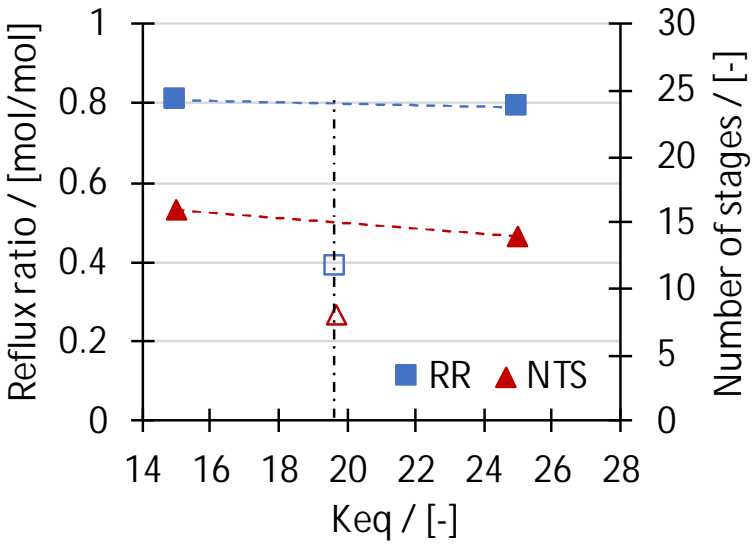

(b)

Figure 6. Case 2 - 2-ethylhexyl acetate synthesis via esterification (a) The predicted boundary line of the RD applicability within the shaded area and the actual boundary line of the RD applicability indicated by the solid line; (b) Reflux ratio and the number of theoretical stages: solid points $=$ estimate; open points $=$ rigorous simulation results. 


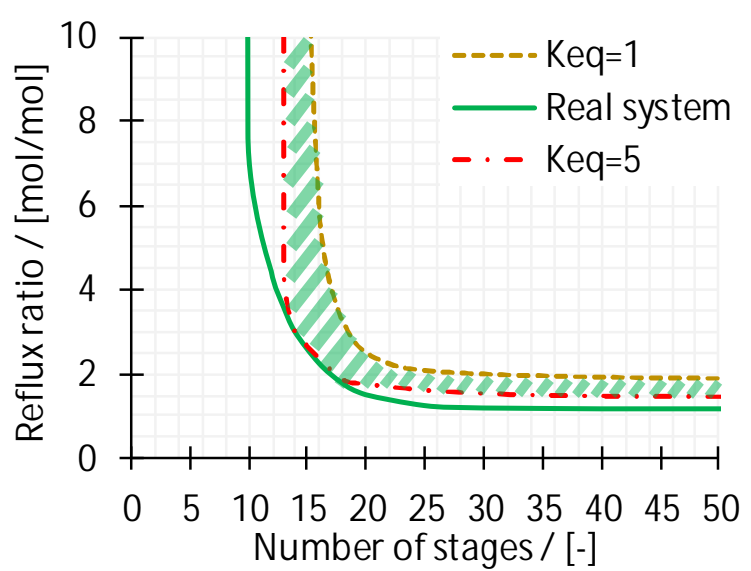

(a)

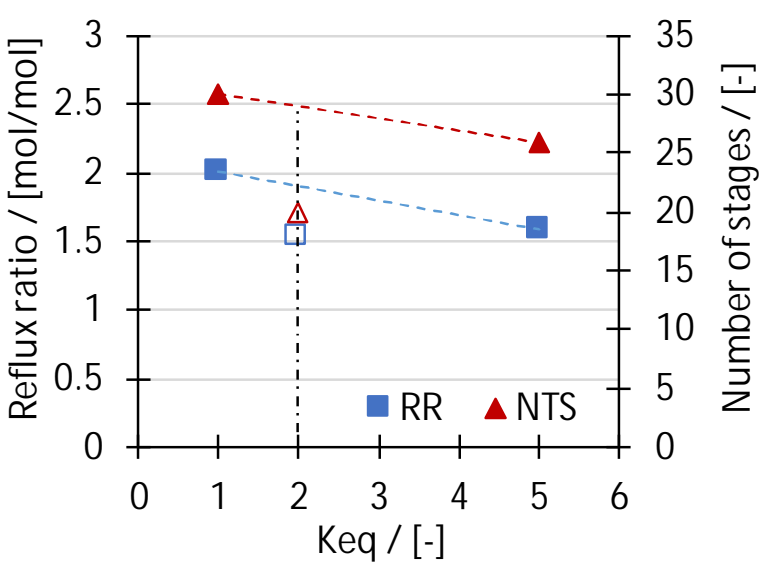

(b)

Figure 7. Case 3 - amyl acetate production via esterification (a) The predicted boundary line 5

6 7 8

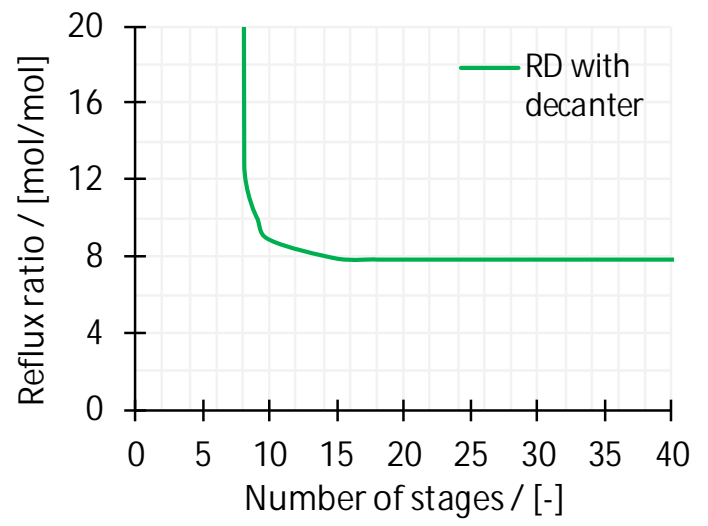

(a)

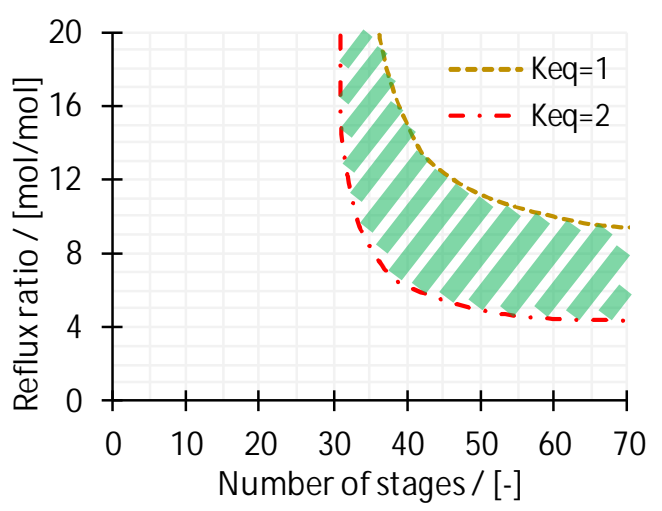

(b)

Figure 8. (a) The actual boundary line of the applicability area of case 4 - butyl acetate synthesis via esterification - for a heterogeneous reactive distillation setup and (b) the predicted boundary line of the applicability area of case 5 - transesterification of methyl acetate and butanol - within the shaded area. 


\title{
Supporting Information
}

\section{A systematic workflow for assessing the applicability of reactive distillation for quaternary mixtures using a mapping method}

\author{
Rahma Muthia ${ }^{1}$, Megan Jobson ${ }^{1}$, Anton A. Kiss ${ }^{1,2 *}$ \\ ${ }^{1}$ Department of Chemical Engineering and Analytical Science, The University of Manchester, \\ Sackville Street, Manchester, M13 9PL, United Kingdom \\ ${ }^{2}$ Sustainable Process Technology Group, Faculty of Science and Technology, \\ University of Twente, PO Box 217, 7500 AE, Enschede, The Netherlands \\ *Corresponding author: tony.kiss@manchester.ac.uk, Tel: +44 1613068759
}




\section{Multiple configurations in an applicability graph of reactive distillation}

Figure S1 (a) shows the applicability graph of reactive distillation for an equilibrium-limited reaction in group $\mathrm{I}_{\mathrm{p}}\left(\mathrm{T}_{\mathrm{b}, \mathrm{C}}<\mathrm{T}_{\mathrm{b}, \mathrm{A}}<\mathrm{T}_{\mathrm{b}, \mathrm{B}}<\mathrm{T}_{\mathrm{b}, \mathrm{D}}\right)$, considering $\alpha_{\mathrm{AB}}=1.5, \alpha_{\mathrm{CA}}=2$ and $\alpha_{\mathrm{BD}}=2$ at $\mathrm{K}_{\mathrm{eq}}$ $=0.1$. The applicability graph is relevant for the product purity of $\geq 99$ mol\%. For this case, $2 \cdot \mathrm{NTS}_{\min }=36$. Close to the boundary line at NTS $=36$, there are multiple configurations available with various combinations of rectifying, reactive and stripping stages - their numbers of reactive stages are highlighted in Figure S1 (b). Some multiple configurations are given in details in table $\mathrm{S} 1$, in which within only $3 \%$ of RR change, at least there are 17 possible RD configurations.
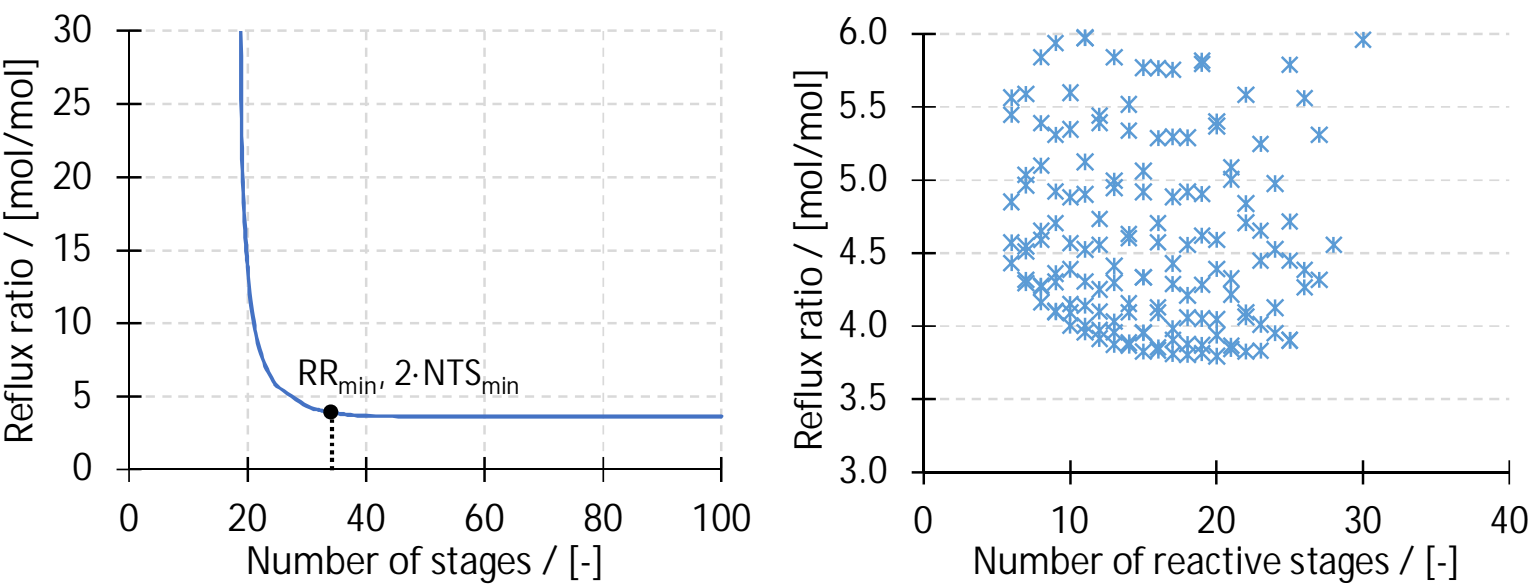

Figure S1. (a) Applicability graph of equilibrium-limited reaction $\left(\alpha_{\mathrm{AB}}=1.5, \alpha_{\mathrm{CA}}=2, \alpha_{\mathrm{BD}}=2\right.$, $\mathrm{K}_{\mathrm{eq}}=0.1$ ); (b) Number of reactive stages required for different column configurations (NTS = $2 \cdot \mathrm{NTS}_{\min }=36$ ), according to the Supporting Information provided in (Muthia et al., 2018).

Table S1. Multiple column configurations for an equilibrium-limited reaction, considering $\left(\alpha_{\mathrm{AB}}\right.$ $=1.5, \alpha_{\mathrm{CA}}=2, \alpha_{\mathrm{BD}}=2, \mathrm{~K}_{\mathrm{eq}}=0.1$ ), according to the Supporting Information provided in (Muthia et al., 2018).

\begin{tabular}{ccccc}
\hline $\begin{array}{c}\text { Number of } \\
\text { theoretical } \\
\text { stages }\end{array}$ & Reflux ratio & $\begin{array}{c}\text { Number of } \\
\text { rectifying } \\
\text { stages }\end{array}$ & $\begin{array}{c}\text { Number of } \\
\text { reactive } \\
\text { stages }\end{array}$ & $\begin{array}{c}\text { Number of } \\
\text { stripping } \\
\text { stages }\end{array}$ \\
\hline 36 & 3.795 & 7 & 20 & 9 \\
\hline 36 & 3.802 & 8 & 18 & 10 \\
\hline 36 & 3.807 & 8 & 17 & 11 \\
\hline 36 & 3.816 & 7 & 19 & 10 \\
\hline 36 & 3.826 & 6 & 22 & 8 \\
\hline 36 & 3.827 & 9 & 15 & 12 \\
\hline 36 & 3.831 & 6 & 23 & 7 \\
\hline 36 & 3.834 & 9 & 16 & 11 \\
\hline 36 & 3.843 & 7 & 21 & 8 \\
\hline 36 & 3.855 & 8 & 16 & 12 \\
\hline
\end{tabular}




\begin{tabular}{ccccc}
\hline 36 & 3.866 & 6 & 21 & 9 \\
\hline 36 & 3.867 & 9 & 14 & 13 \\
\hline 36 & 3.868 & 8 & 19 & 9 \\
\hline 36 & 3.875 & 10 & 13 & 13 \\
\hline 36 & 3.875 & 7 & 18 & 11 \\
\hline 36 & 3.888 & 10 & 14 & 12 \\
\hline 36 & 3.902 & 5 & 25 & 6
\end{tabular}

\section{Ratio of the Damköhler number to the chemical equilibrium constant}

The ratio between the Damköhler number and the chemical equilibrium constant is assessed using two case studies that represent non-ideal reaction systems - synthesis of methyl acetate and hydrolysis of methyl lactate.

$$
\begin{array}{rcccr}
\multicolumn{4}{r}{\text { Methanol + acetic acid } \rightleftharpoons \text { methyl acetate + water }} \\
\mathrm{T}_{\mathrm{b}}\left({ }^{\circ} \mathrm{C}\right) & 64.7 & 118 & 56.9 & 100 \\
& \text { Water }+ \text { methyl lactate } & \gtrless & \text { methanol + lactic acid } \\
\mathrm{T}_{\mathrm{b}}\left({ }^{\circ} \mathrm{C}\right) & 100 & 144.8 & 64.7 & 216.9
\end{array}
$$

The chemical equilibrium constant and the forward reaction rate constant $\left(\mathrm{mol} \mathrm{g}_{\mathrm{cat}}{ }^{-1} \mathrm{~min}^{-1}\right)$ relationships for the synthesis of methyl acetate are presented by Pöpken et al. (2000) as:

$$
\begin{aligned}
& \ln \left(K_{e q}\right)=-3.82+2408.65 / T \\
& k_{f}=4.94 \cdot 10^{2} \cdot \exp (-49,190 / R \cdot T)
\end{aligned}
$$

The chemical equilibrium constant and the forward reaction rate constant $\left(\mathrm{mol} \mathrm{g}_{\mathrm{cat}}{ }^{-1} \mathrm{~min}^{-1}\right)$ relationships for the hydrolysis of methyl lactate are provided by Sanz et al. (2004),

$$
\begin{aligned}
& \ln \left(K_{e q}\right)=2.6-1954.2 / T \\
& k_{f}=1.65 \cdot 10^{5} \cdot \exp (-50,910 / R \cdot T)
\end{aligned}
$$

In the first case, two homogeneous azeotropes exist between methyl acetate (65.9 mol\%)methanol $(34.1 \mathrm{~mol} \%)$ at $53.7^{\circ} \mathrm{C}$ and methyl acetate $(89 \mathrm{~mol} \%)$-water $(11 \mathrm{~mol} \%)$ at $56.4{ }^{\circ} \mathrm{C}$. In the second case, there is an azeotrope identified between water $(97 \mathrm{~mol} \%)$ and methyl lactate (3 $\mathrm{mol} \%$ ) at $99.8^{\circ} \mathrm{C}$.

Figure S2 shows applicability graphs for both case studies generated using rigorous simulations in Aspen Plus. It is observed that the applicability areas of both kinetically controlled and equilibrium-limited reactions are similar for $\mathrm{Da} / \mathrm{K}_{\mathrm{eq}} \geq 5$. 

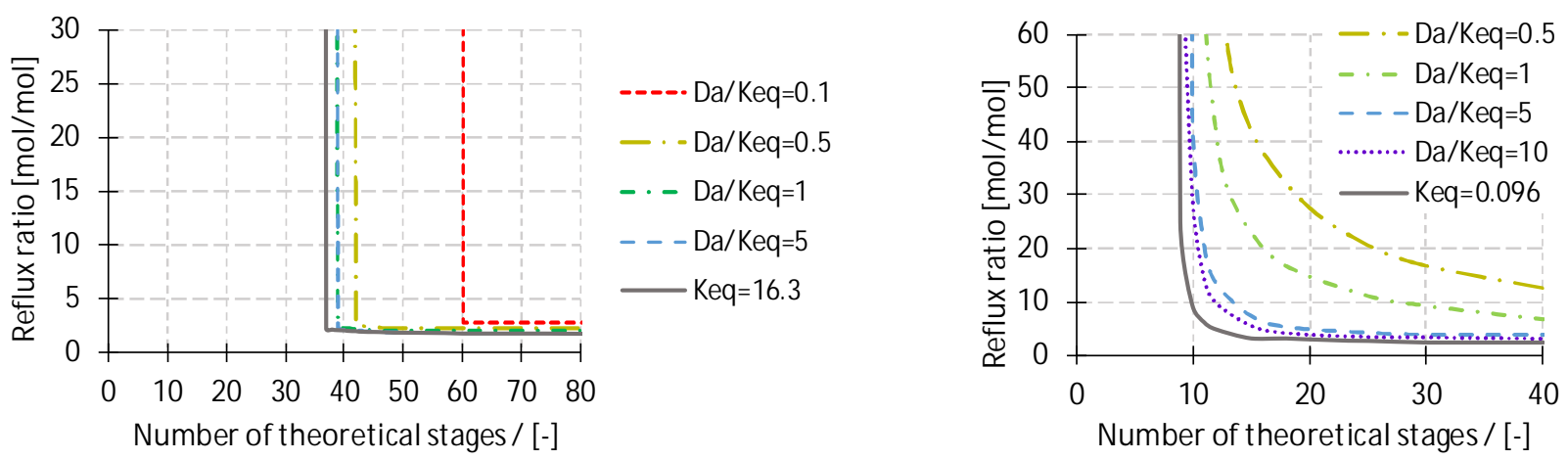

Figure S2. Applicability graphs of reactive distillation for (a) synthesis of methyl acetate;

(b) hydrolysis of methyl lactate

\section{Preliminary economic evaluation of reactive distillation}

The systematic workflow presented in this work allows engineers in the chemical industries to assess the applicability of reactive distillation, based on a mapping method that we have developed (Muthia et al., 2018, 2019a, 2019b). When reactive distillation is applicable, preliminary economic evaluation is conducted for the chosen reactive distillation configuration, by using adapted steps of cost estimation for conventional distillation. Complete procedures of economic evaluation for conventional distillation are explained elsewhere (Douglas, 1998; Seider et al., 2010; Towler and Sinnott, 2012).

Total annualized cost (TAC) is a key variable to compare the reactive distillation process with other conventional or hybrid systems. It comprises two elements: annualized investment cost (AIC) defined as the total investment cost (TIC) relative to pay-back period (PBP), and total operating cost (TOC). The components of AIC include the costs of column shell and internals, condenser, reboiler, reflux drum and any additional equipment (e.g. pumps). TOC include the costs of cooling water, steam and catalyst. Eqs. (1)-(5) present some important cost correlations for TAC, TIC and TOC (Douglas, 1998), where costs are updated from 1998 (Marshall and Swift index, $M \& S=280)$ to the current year using the current value of the $M \& S$ index $(M \& S=$ 1638.2 at the end of 2018).

$$
\begin{aligned}
& T A C=\frac{T I C}{P B P}+T O C \\
& T I C_{R D, \text { Shell }}=\left(\frac{M \& S}{280}\right) \cdot 101.9 \cdot D^{1.066} \cdot H^{0.802} \cdot\left(2.18+F_{C}\right) \cdot F_{\text {lang }}
\end{aligned}
$$




$$
\begin{aligned}
& T I C_{R D, \text { Internal }}=\left(\frac{M \& S}{280}\right) \cdot 4.7 \cdot D^{1.55} \cdot H \cdot F_{C} \cdot F_{\text {lang }} \\
& T I C_{c}=\left(\frac{M \& S}{280}\right) \cdot 101.3 \cdot A_{c}^{0.65} \cdot\left(2.29+F_{c}\right) \cdot F_{\text {lang }} \\
& T I C_{r}=\left(\frac{M \& S}{280}\right) \cdot 101.3 \cdot A_{r}^{0.65} \cdot\left(2.29+F_{c}\right) \cdot F_{\text {lang }}
\end{aligned}
$$

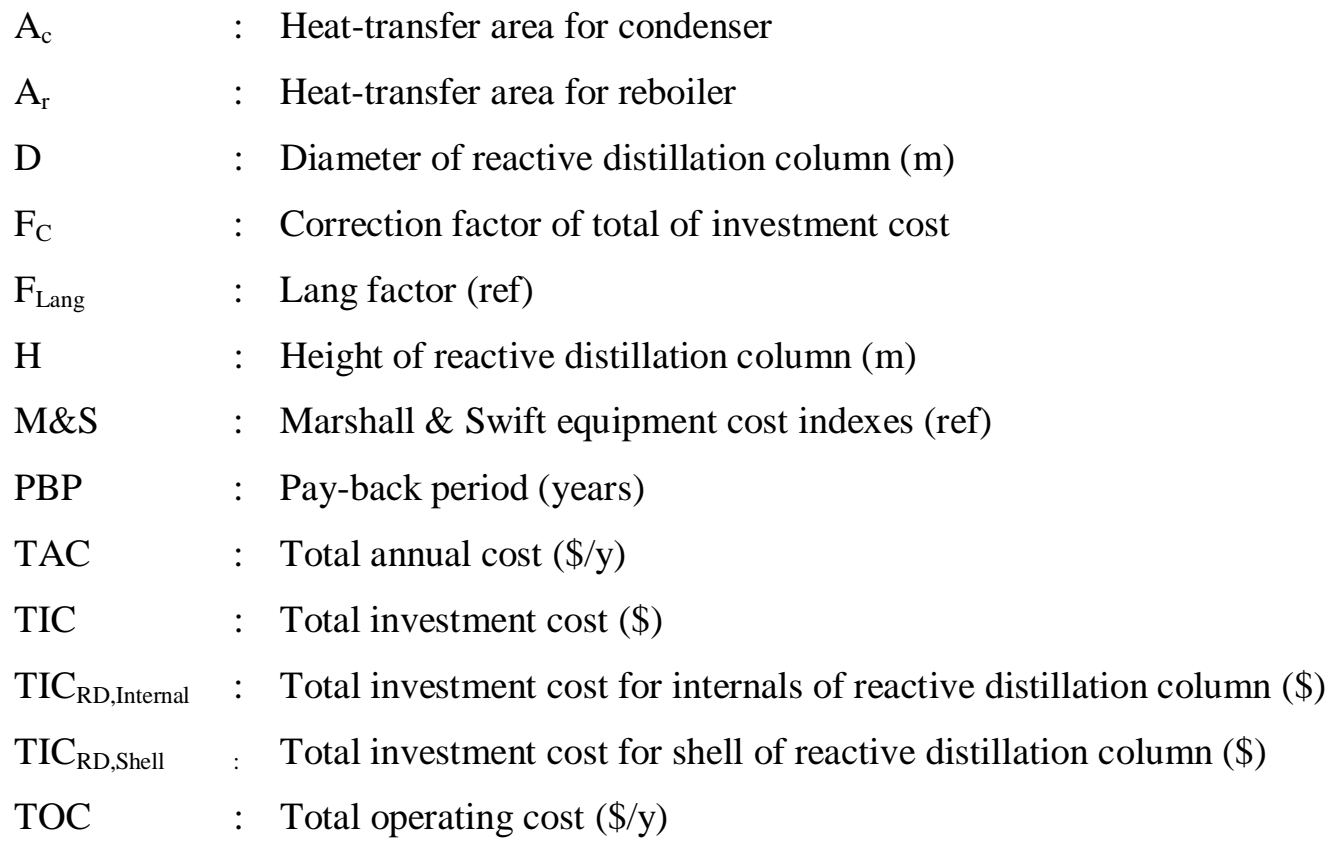

\section{Calculations of representative relative volatilities of compounds}

Eq. (6) defines the relative volatility of $\mathrm{i}$ and $\mathrm{j}$ in terms of the liquid and vapour mole fractions $(x$ and $y$ ) at phase equilibrium:

$$
\alpha_{i j}=\frac{K_{i}}{K_{j}}=\frac{\left(\frac{y_{i}}{x_{i}}\right)}{\left(\frac{y_{j}}{x_{j}}\right)}
$$

Tables S2-S6 provide the compositions of mixtures in vapor and liquid phases for 99 mol\% pure products and $50 \mathrm{~mol} \%$ pure reactants. The data given is applied at atmospheric pressure and it is assumed that the stream is at saturated conditions (i.e. liquid at boiling point). 
Table S2. Case 1: Vapor and liquid compositions of mixtures (methyl acetate production via esterification)

\begin{tabular}{|c|c|c|c|c|c|c|c|}
\hline Feed composition & $\mathrm{y}_{\mathrm{i}}$ & $\mathrm{x}_{\mathrm{i}}$ & $\mathrm{y}_{\mathrm{j}}$ & $\mathrm{x}_{\mathrm{j}}$ & $\mathrm{K}_{\mathrm{i}}$ & $\mathrm{K}_{\mathrm{j}}$ & $\alpha_{\mathrm{ij}}$ \\
\hline 99 mol\% of methyl acetate (i) & 0.98 & 0.99 & 0.02 & 0.01 & 0.99 & 1.92 & 0.52 \\
\hline \multicolumn{8}{|l|}{1 mol\% of methanol (j) } \\
\hline $50 \mathrm{~mol} \%$ of methanol (i) & 0.86 & 0.50 & 0.14 & 0.50 & 1.73 & 0.27 & 6.28 \\
\hline \multicolumn{8}{|l|}{50 mol\% of acetic acid (j) } \\
\hline $1 \mathrm{~mol} \%$ of acetic acid (i) & 0.006 & 0.01 & 0.99 & 0.99 & 0.60 & 1.00 & 1.66 \\
\hline
\end{tabular}

Table S3. Case 2: Vapor and liquid compositions of mixtures (2-ethylhexyl acrylate synthesis via esterification)

\begin{tabular}{lccccccc}
\hline \multicolumn{1}{c}{ Feed composition } & $\mathrm{y}_{\mathrm{i}}$ & $\mathrm{x}_{\mathrm{i}}$ & $\mathrm{y}_{\mathrm{j}}$ & $\mathrm{x}_{\mathrm{j}}$ & $\mathrm{K}_{\mathrm{i}}$ & $\mathrm{K}_{\mathrm{j}}$ & $\alpha_{\mathrm{ij}}$ \\
\hline 99 mol\% of water (i) & 0.99 & 0.99 & 0.006 & 0.01 & 1.00 & 0.62 & 1.63 \\
$1 \mathrm{~mol} \%$ of acrylic acid (j) & & & & & & & \\
\hline $\begin{array}{l}50 \text { mol\% of acrylic acid (i) } \\
50 \text { mol\% of 2-ethylhexanol (j) }\end{array}$ & 0.80 & 0.50 & 0.20 & 0.50 & 1.60 & 0.40 & 3.96 \\
\hline $\begin{array}{l}1 \text { mol\% of 2-ethylhexanol (i) } \\
99 \text { mol\% of 2-ethylhexyl }\end{array}$ & 0.05 & 0.01 & 0.95 & 0.99 & 5.04 & 0.96 & 5.25 \\
acrylate (j) & & & & & & & \\
\end{tabular}

Table S4. Case 3: Vapor and liquid compositions of mixtures (amyl acetate production via esterification)

\begin{tabular}{lccccccc}
\hline \multicolumn{1}{c}{ Feed composition } & $\mathrm{y}_{\mathrm{i}}$ & $\mathrm{x}_{\mathrm{i}}$ & $\mathrm{y}_{\mathrm{j}}$ & $\mathrm{x}_{\mathrm{j}}$ & $\mathrm{K}_{\mathrm{i}}$ & $\mathrm{K}_{\mathrm{j}}$ & $\alpha_{\mathrm{ij}}$ \\
\hline $99 \mathrm{~mol} \%$ of water (i) and 1 & 1.00 & 0.99 & 0.005 & 0.01 & 1.00 & 0.52 & 1.95 \\
mol\% of acetic acid (j) & & & & & & & \\
\hline $\begin{array}{l}50 \text { mol\% of acetic acid (i) and 50 } \\
\text { mol\% of amyl alcohol (j) }\end{array}$ & 0.63 & 0.50 & 0.37 & 0.50 & 1.27 & 0.73 & 1.73 \\
\hline $\begin{array}{l}1 \text { mol\% of amyl alcohol (i) and } \\
99 \text { mol\% of amyl acetate (j) }\end{array}$ & & & & & & & \\
\hline
\end{tabular}


Table S5. Case 4: Vapor and liquid compositions of mixtures (n-butyl acetate synthesis via esterification)

\begin{tabular}{|c|c|c|c|c|c|c|c|}
\hline Feed composition & $\mathrm{y}_{\mathrm{i}}$ & $\mathrm{x}_{\mathrm{i}}$ & $\mathrm{y}_{\mathrm{j}}$ & $\mathrm{x}_{\mathrm{j}}$ & $\mathrm{K}_{\mathrm{i}}$ & $\mathrm{K}_{\mathrm{j}}$ & $\alpha_{i j}$ \\
\hline $\begin{array}{l}99 \text { mol\% of water (i) and } 1 \\
\text { mol\% of acetic acid (j) }\end{array}$ & 0.99 & 0.99 & 0.007 & 0.01 & 1.00 & 0.70 & 1.42 \\
\hline $\begin{array}{l}50 \text { mol\% of acetic acid (i) and } 50 \\
\text { mol\% of n-butanol (j) }\end{array}$ & 0.49 & 0.50 & 0.51 & 0.50 & 0.98 & 1.02 & 0.95 \\
\hline $\begin{array}{l}1 \text { mol\% of n-butanol (i) and } 99 \\
\text { mol\% of n-butyl acetate (j) }\end{array}$ & 0.98 & 0.99 & 0.02 & 0.01 & 0.99 & 1.75 & 0.57 \\
\hline
\end{tabular}

Table S6. Case 5: Vapor and liquid compositions of mixtures (transesterification of methyl acetate and n-butanol)

\begin{tabular}{lccccccc}
\hline \multicolumn{1}{c}{ Feed composition } & $\mathrm{y}_{\mathrm{i}}$ & $\mathrm{x}_{\mathrm{i}}$ & $\mathrm{y}_{\mathrm{j}}$ & $\mathrm{x}_{\mathrm{j}}$ & $\mathrm{K}_{\mathrm{i}}$ & $\mathrm{K}_{\mathrm{j}}$ & $\alpha_{\mathrm{ij}}$ \\
\hline $\begin{array}{l}1 \mathrm{~mol} \% \text { of methyl acetate (i) and } \\
\text { 99 mol\% of methanol (j) }\end{array}$ & 0.03 & 0.01 & 0.97 & 0.99 & 3.29 & 0.98 & 3.37 \\
\hline $\begin{array}{l}50 \mathrm{~mol} \% \text { of methyl acetate (i) } \\
\text { and } 50 \text { mol\% of n-butanol (j) }\end{array}$ & 0.92 & 0.50 & 0.08 & 0.50 & 1.85 & 0.15 & 12.0 \\
\hline $\begin{array}{l}1 \mathrm{~mol} \% \text { of n-butanol (i) and 99 } \\
\text { mol\% of n-butyl acetate (j) }\end{array}$ & & & & & & & \\
\hline
\end{tabular}

\section{Applicability assessment of Case 1 (methyl acetate production via esterification)}

The position of feed stages within the reactive zone notably affects the size of the applicability graph of case study 1 , as an immediate contact between reactants contributes to minimize the formation of azeotrope between reactant and product. Figure S2 presents the applicability graphs of reactive distillation for fixed feed stages at the top and the bottom stages of the reactive zone and varied feed stages within the reactive zone. 


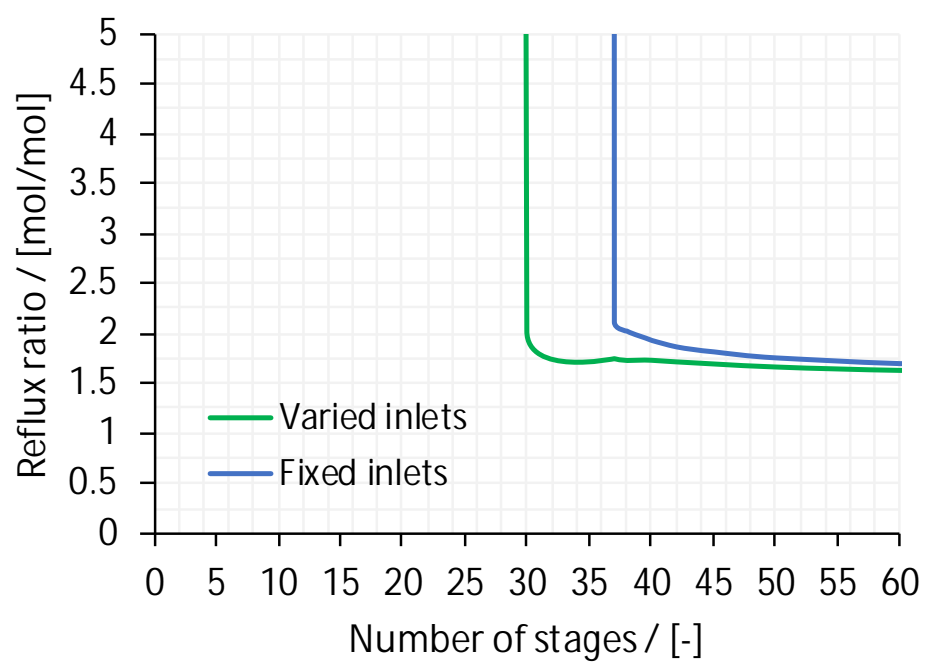

Figure S3. Applicability graphs of Case 1 obtained from rigorous simulations

Figure S3 shows the composition profile of a column configuration (2 rectifying, 51 reactive and 7 stripping stages, and reflux ratio of 1.8) that exists close to the boundary line of the applicability graph for Case 1 . The high chemical equilibrium constant of this system $\left(\mathrm{K}_{\mathrm{eq}}=\right.$ 16.3 at $91.4^{\circ} \mathrm{C}$ ) allows a high conversion of reactants in the reactive section of the column. In this system classified into group $\operatorname{III}_{\mathrm{p}}\left(\mathrm{T}_{\mathrm{b}, \mathrm{C}}<\mathrm{T}_{\mathrm{b}, \mathrm{A}}<\mathrm{T}_{\mathrm{b}, \mathrm{D}}<\mathrm{T}_{\mathrm{b}, \mathrm{B}}\right)$, it is crucial to prevent reactant B from reaching the stripping section, as it is the heaviest component that could interfere the high purity of product D.

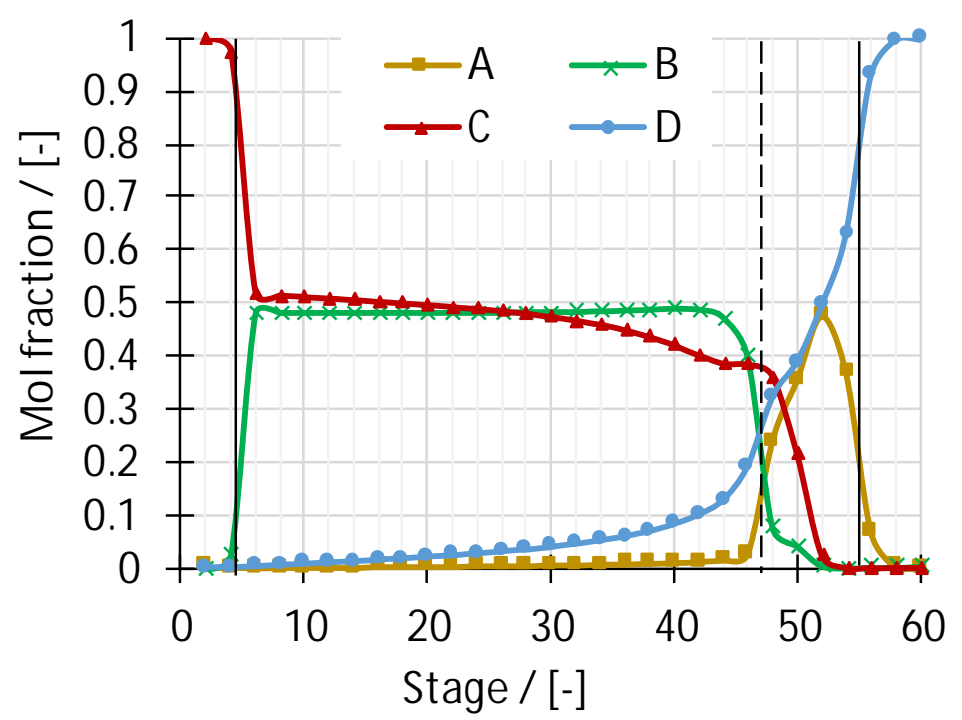

Figure S4. The composition profile of a column configuration for Case 1. The solid vertical lines depict the start and end of reactive section. The dashed line is the feed stage of reactant A, while the feed stage of reactant B overlaps with the start of reactive section. 


\section{References}

1. Douglas J.M., 1988. Cost Data. In: B.J. Clark and J.W. Bradley (Eds.), Conceptual design of chemical processes. McGraw-Hill Book, USA, pp. 572-575.

2. Muthia, R., Jobson, M., Kiss, A.A., 2019a. Innovative mapping method for screening reactive distillation designs. Comput. Aided Chem. Eng. 46, 739-744.

3. Muthia, R., Reijneveld, A.G.T., van der Ham, A.G.J., ten Kate, A.J.B., Bargeman, G., Kersten, S.R.A., Kiss, A.A., 2018. Novel method for mapping the applicability of reactive distillation. Chem. Eng. Process. Process Intensif. 128, 263-275.

4. Muthia, R., van der Ham, A.G.J., Jobson, M., Kiss, A.A., 2019b. Effect of boiling point rankings and feed locations on the applicability of reactive distillation to quaternary systems. Chem. Eng. Res. Des. 145, 184-193.

5. Pöpken, T., Götze, L., Gmehling, J., 2000. Reaction kinetics and chemical equilibrium of homogeneously and heterogeneusly catalyzed acetic acid esterification with methanol and methyl acetate hydrolysis. Ind. Eng. Chem. Res. 39, 2601-2611.

6. Sanz, M. T., Murga, R., Beltrán, S., Cabezas J. L., Coca, J., 2004. Kinetic study for the reactive system of lactic acid esterification with methanol: methyl lactate hydrolysis reaction. Ind. Eng. Chem. Res. 43, 2049-2053.

7. Seider, W.D., Seader, J.D., Lewin, D.R., Widagdo, S., 2010. Product and process design principles: Synthesis, analysis, and design. John Wiley and Sons, Inc., USA.

8. Towler, G., Sinnott, R., 2012. Chemical Engineering Design: Principles, Practice and Economics of Plant and Process Design. Butterworth-Heinemann, USA. 